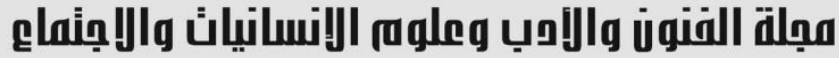

Journal of Arts, Literature, Humanities and Social Sciences www.jalhss.com

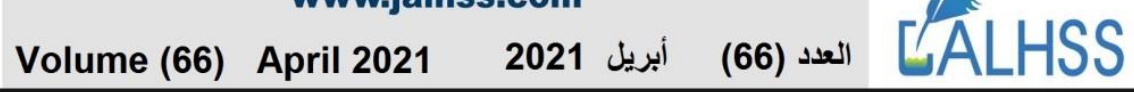

\section{تحوير وتوظيف الزخارف العباسية بطريقه حديثة في ملابس الفتيات \\ (دراسة وصفية)}

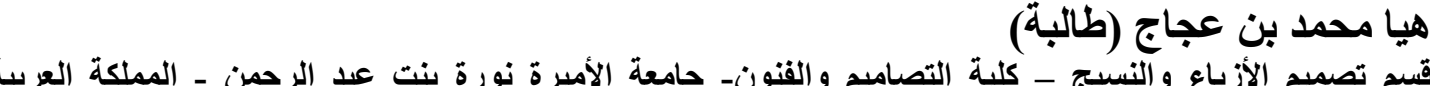
قسم تصميم الأزياء والنسيج - كلية التصاميم والفنون- جامعة الأميرة نورة بنت عبد الرحمن - المملكة العربية منار عبدالله الطريقي (طالبة) قسم تصميم الأزياء والنسيج - كلية التصاميم والفنون- جامعة الأميرة نورة بنت عبد الرحمن - المملكة العربية السعودية أصيم

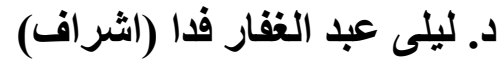
أستاذ مشارث ـ قدم تصميم الأزياء والنسيج - كلية التصاميم و الفنون- جامعة الأميرة نورة بنت عبد الرحمن - المملكة العربية السعودية البثرية laila.a.feda@gmail.com البريد الاكترونية

المداخص

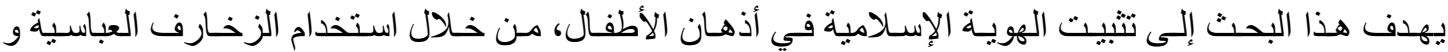

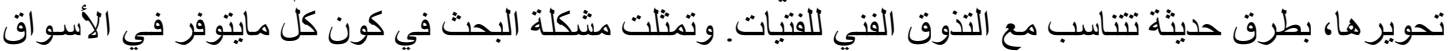

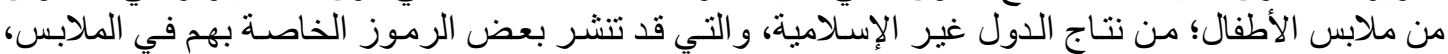

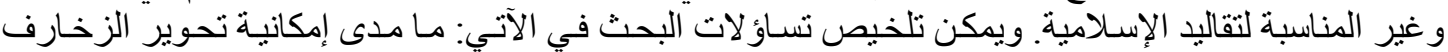

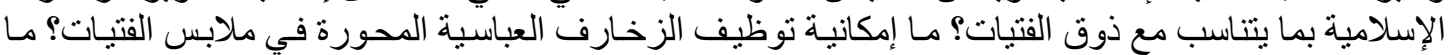

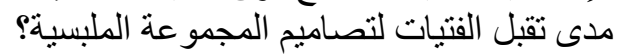

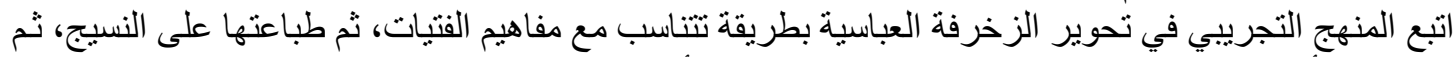

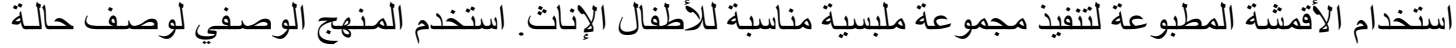

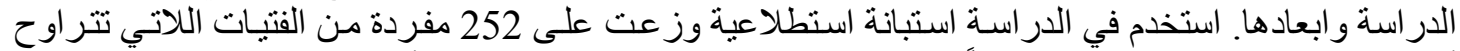

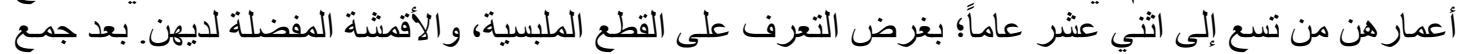

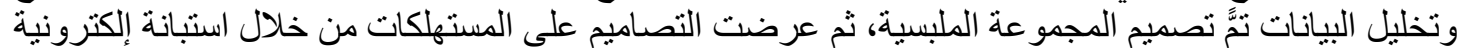

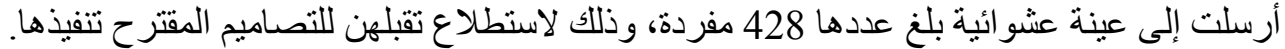

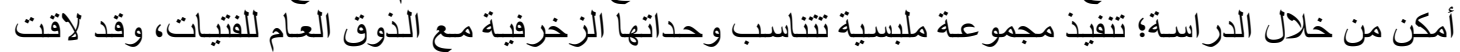

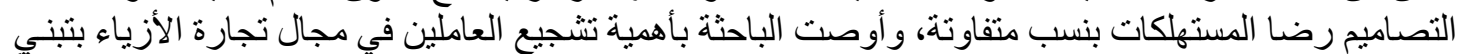

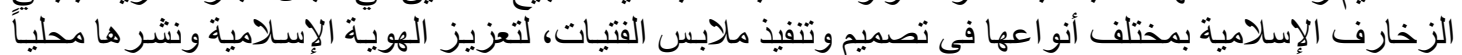
و عالمباً. 


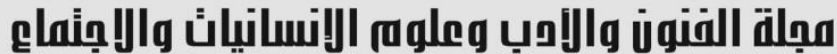

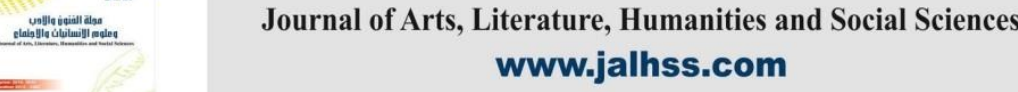

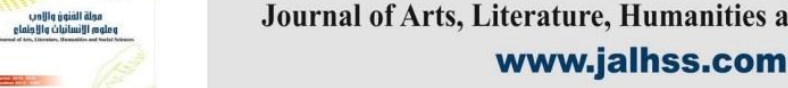

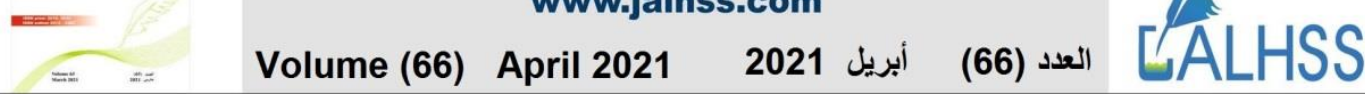 \\ Modern Alteration and Utilization of Abbasid Ornament on Girls' Clothing (Descriptive Research)
}

\author{
Haya Mohammed bin Ajaj (student) \\ Department of Fashion and Textile Design - College of Design and Art - Princess Noura Bint \\ Abdul Rahman University - Kingdom of Saudi Arabia \\ Manar Abdullah Al-Tariki (Student) \\ Department of Fashion and Textile Design - College of Design and Art - Princess Noura Bint \\ Abdul Rahman University - Kingdom of Saudi Arabia \\ Dr. Laila Abdel Ghaffar Feda (Supervision) \\ Associate Professor - Department of Fashion and Textile Design - College of Design and Art - \\ Princess Noura Bint Abdul Rahman University - Kingdom of Saudi Arabia \\ Email: laila.a.feda@gmail.com
}

\begin{abstract}
The research aims to strengthen the Islamic Identity in children minds by using and altering Abbasid ornament in modern ways aligned with girl's current fashion.

The research problem lays in the fact that all children cloths available in the market are a product of non-Islamic countries that contain some symbols related to their religion.

The research questions can be summarized as follows: To what extent is it possible to alter Islamic ornaments to fit the current fashion? is it possible to utilize modified Abbasid ornaments in girls' clothes? How tolerant are girls to the clothing set designs? The researcher followed the experimental method in altering the Abbasid ornaments in a way that fits current girls' fashion, by printing them on the fabric, then using these fabrics to create a clothing set suitable to female children.

Descriptive approach was used to describe the case study and its dimensions. In order to identify girls' favorite pieces of cloths and fabrics, an exploratory questionnaire was distributed to 252 individual girls between the ages of nine and twelve.

The clothing set was designed after collecting and analyzing the data. The designs were presented through an online questionnaire sent to a random sample of 420 individuals, to explore their preferences of the proposed designs. The research created a clothing set with ornaments that fit girls' current fashion. The designs received relative levels of consumer satisfaction. The researcher emphasizes the importance of encouraging those in the field of fashion business to adopt Islamic ornaments of various types in the design and implementation of girls' clothes, to strengthen and spread the Islamic identity locally and internationally.
\end{abstract}

Keywords: Girls clothes, Abbasid Ornaments, Ornament alteration. 


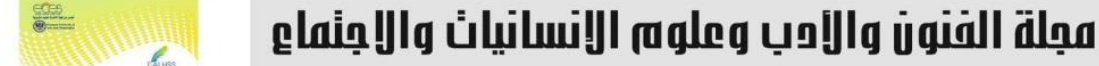 \\ Journal of Arts, Literature, Humanities and Social Sciences \\ www.jalhss.com \\ Volume (66) April 2021 \\ أبريل 2021

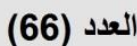

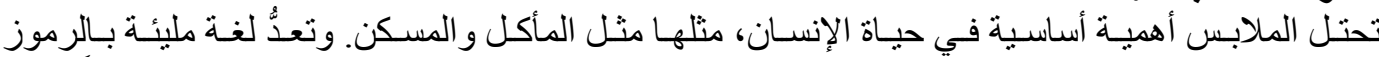

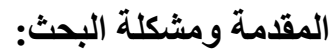

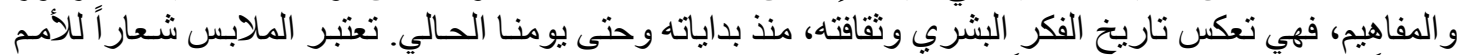

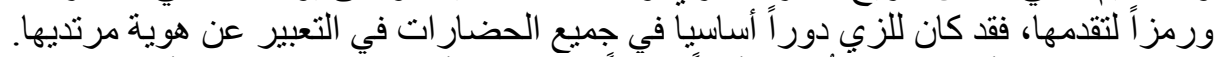

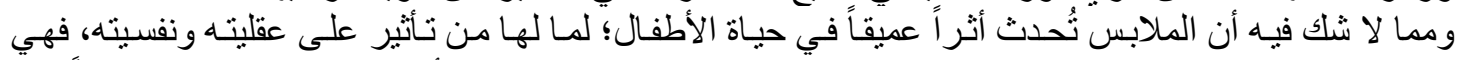

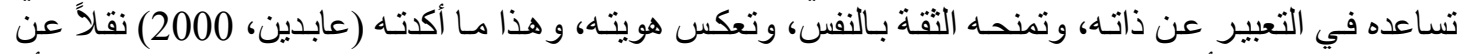

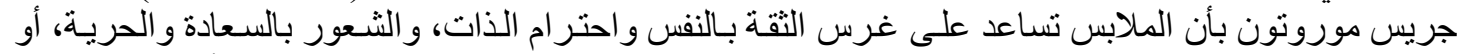

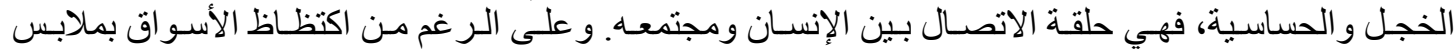

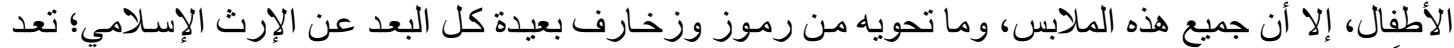

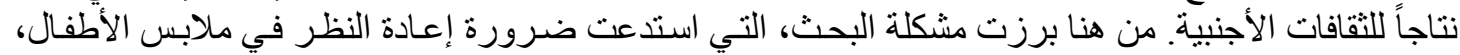

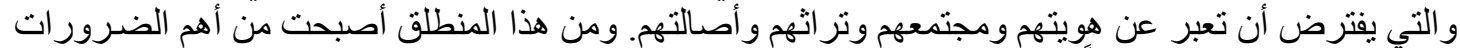
التي تحتاج إلى تفكير جيد وبنَّاء.

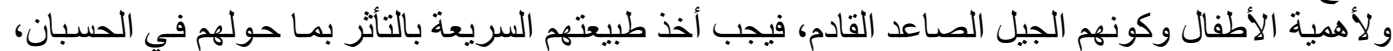

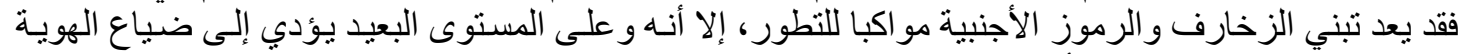

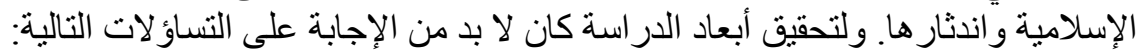

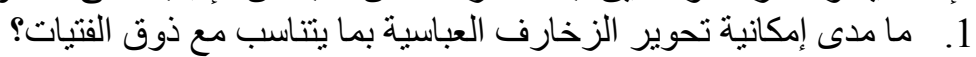

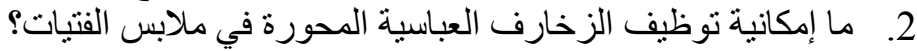
3.

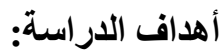

تحوير بعض الزخارف العباسية بما يتناسب مع الذوق الفني للأطفال.

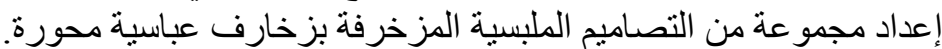
قياس مدى تقبل الفتيات للتصاميم المعدة.

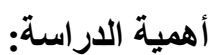

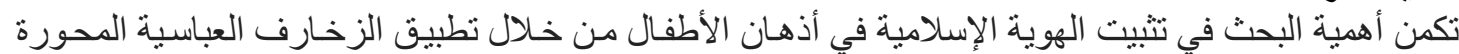

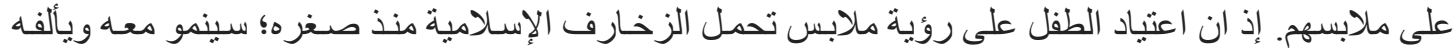

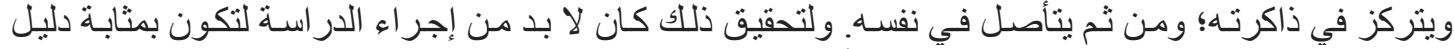
إرشادي لمصنعي النسيج و الملابس الخاصة بألأطفال.

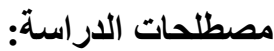

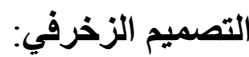

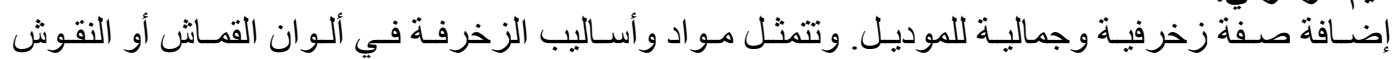

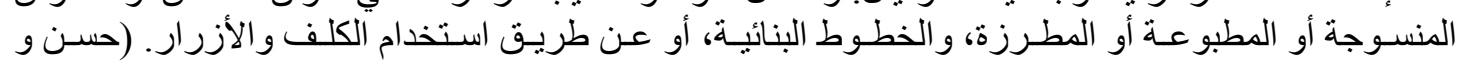
زغلول، 2009).

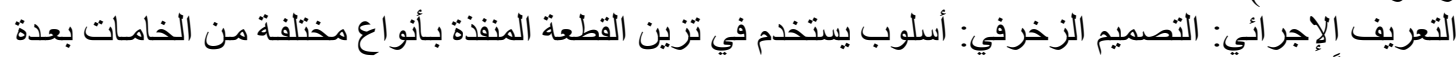

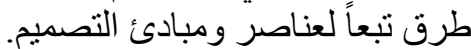

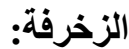

فن تزيين الأشياء بالنقش، أو التطريز، أو التطعيم وغير ذللك. (المعجم الوسيط)

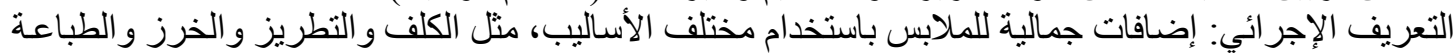
و الصباغة ونحو هاً. التحوير:

يقال حور فـلان الكـلام: غيَّره. (المعجم الر ائد) وترى (الغامدي، 2004) أن التحوير يعني "تغيير شكل العنصر جمالياً دون أن يفقد هويته الأصلية". 


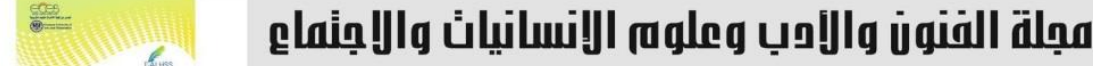 \\ Journal of Arts, Literature, Humanities and Social Sciences \\ www.jalhss.com

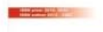 \\ Volume (66) April 2021 \\ أبريل 2021

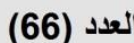

التعريف الإجر ائي: تغبير شكل الزخرفة بأساليب مختلفة كالحذف و التكر ار و الإضـافة و إعـادة الصياغة و غير هـا

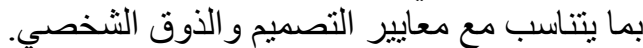

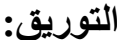

مصطلح يطلق على الزخارف التي يستخدم فيها الجذع و الورقة والزهرة والثمار في أسلوب محوري، يتميز

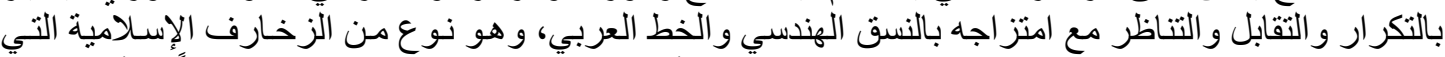

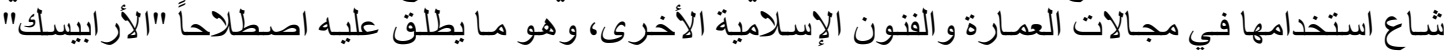

(مليباري و الغامدي، 1414)

برنامج الاليستريتوري، Adobe illustrator

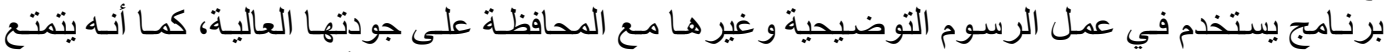

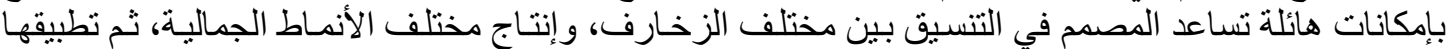
على الأقمشة.

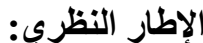

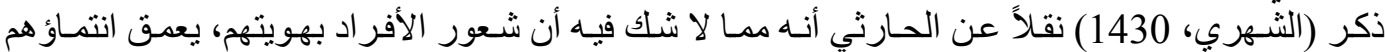

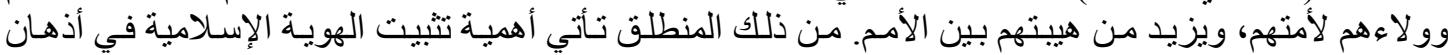

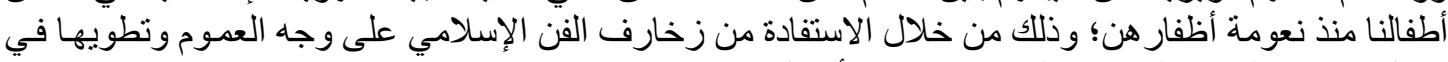

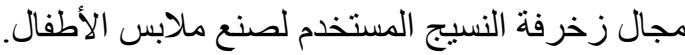

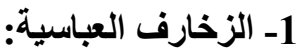

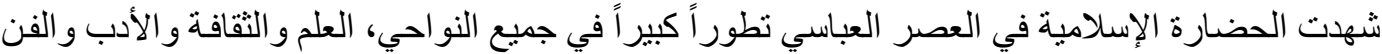

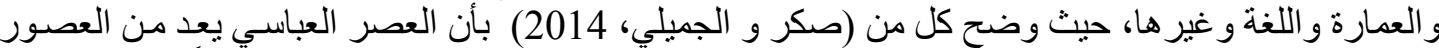

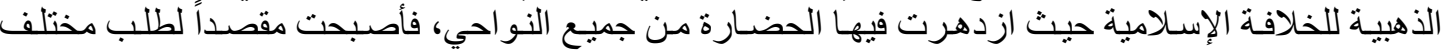

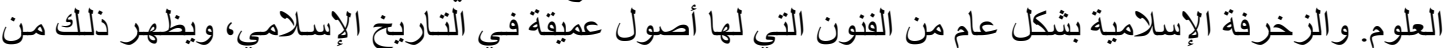

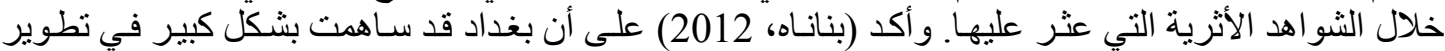

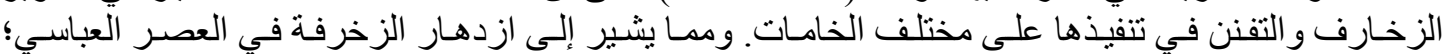

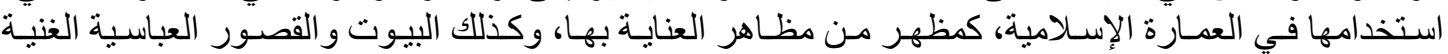

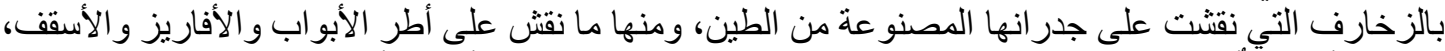

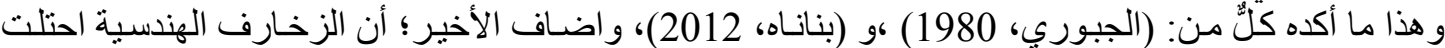
الصدارة بين الزخارف، وتعد المدرسة المستتصرية شاهد عيان على على ذلك.

اعتمدت الزخرفة الهندسية على تكر ار شكل المربع والدائرة، ومن ثم التوصيل بين نقاط التقاطع؛ لإنتاج

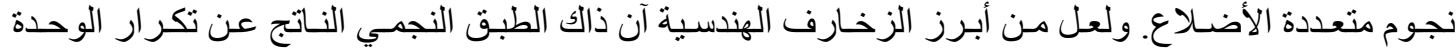

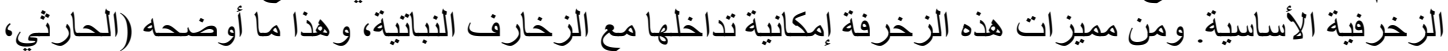

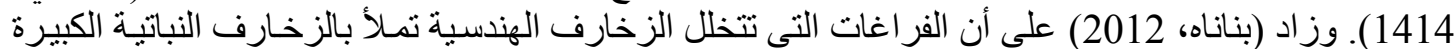

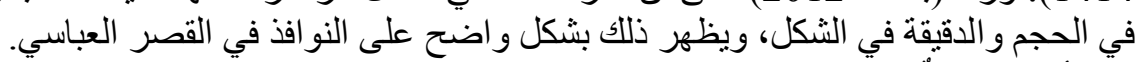

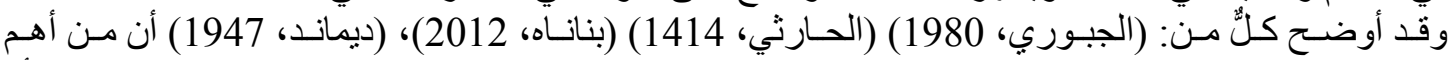

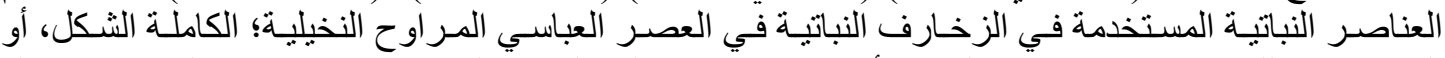

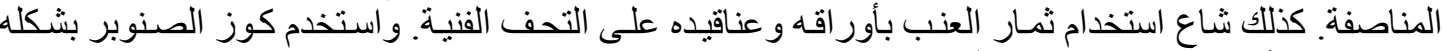

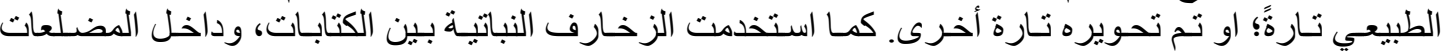

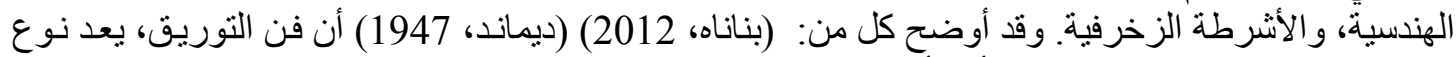

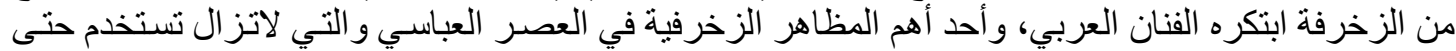

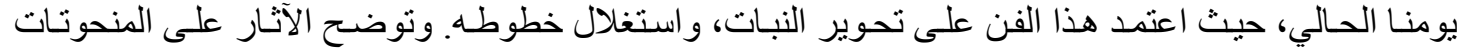

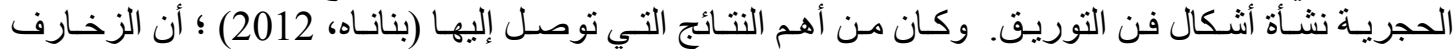




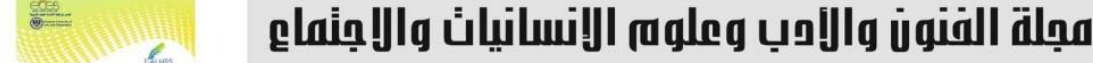 \\ Journal of Arts, Literature, Humanities and Social Sciences www.jalhss.com

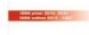 \\ Volume (66) April 2021 \\ أبريل 2021

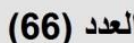

بفرو عها الهندسية و النباتية و الخطية تمثل وحدة متر ابطة بمكنها أن تتأقلم مع أي تصميم، ويمكن أن تجتمـع لتكون وحدة زخرفية متجانسة تؤدي وظائف جمالية.

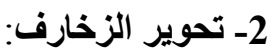

ظهر فن التحوير الإسـامي في العصدر الأمسوي، وبعد ذلك ابتعد الفنـان عن محاكـاة الطبيعـة في العصدر

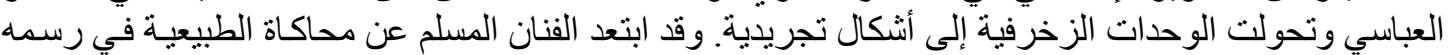

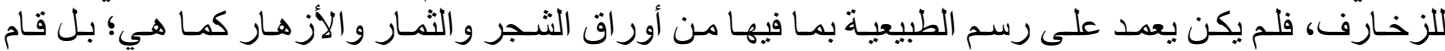

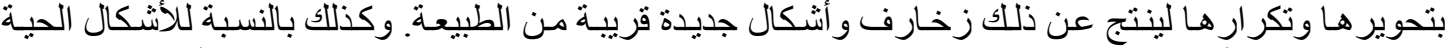

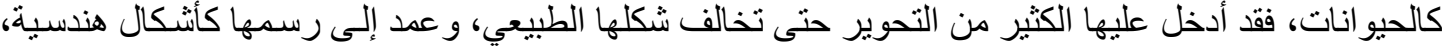
أدخل عليها الكثير من الزخارف النيات النباتية حتى تبتعد عن شكلها الطبيعي، و هذا ما أكدته در اسة (الحارثي، 1414)

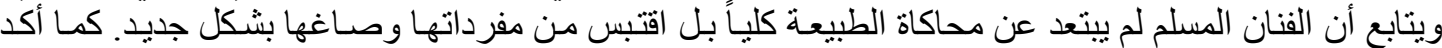

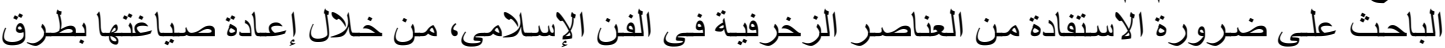

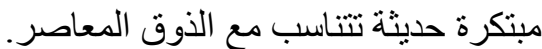
وجاء في در اسة (الغامدي، 2004) أنه يمكن عمل تصميمات مبتكرة من خلانل العناصـر النباتيـة الإسـلامية،

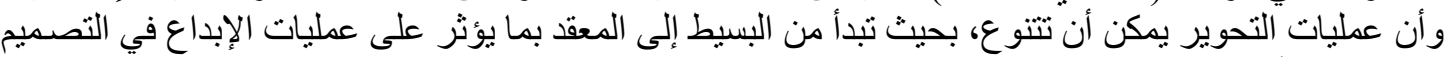

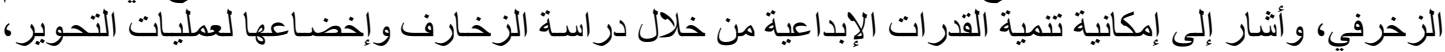

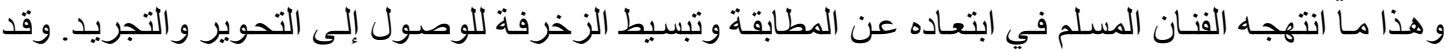

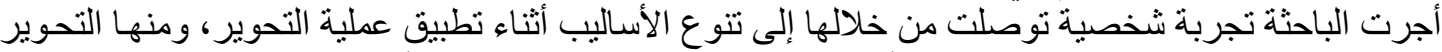

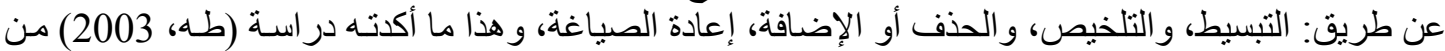

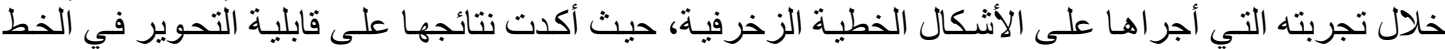

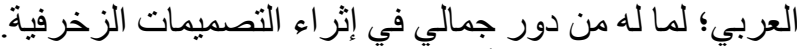
وترى (قربان، 2016) أن معظم عناصر الزخرفة في الفن الإسلامي جاءت من التحوير للأشكال الطبيعيـة، وأن

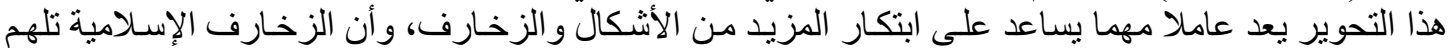

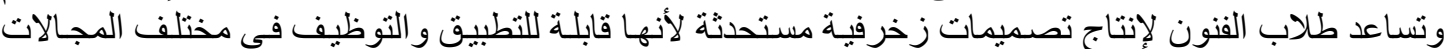

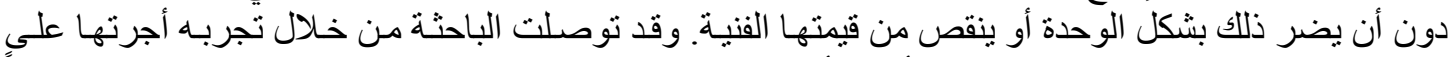

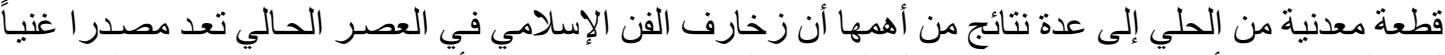

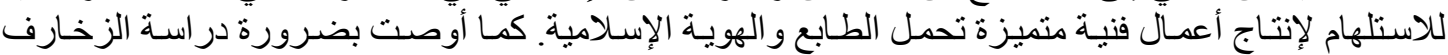
الإسلامية بمنظور جديد بعيد عن المحاكاة والتقليد وعدم اغفال الفنون المعاصرة المستلهمة من الفن الإسلامي.

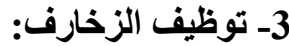

أجرت الباحثة (علي، 2011) در اسة حول عشرين تصميماً لملابس الأطفال من البنات، مستوحاة من أعمال

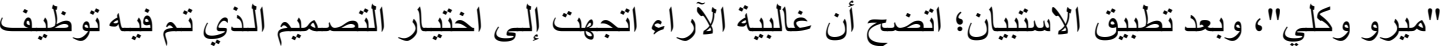

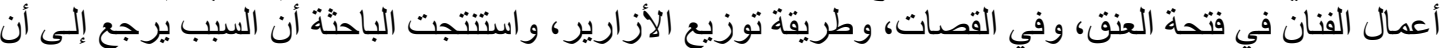

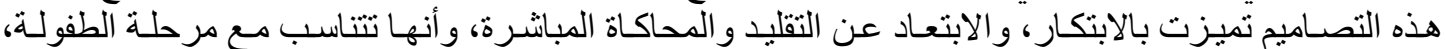

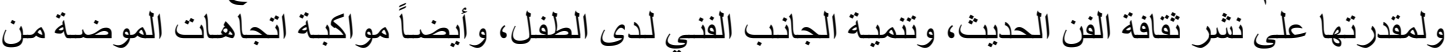

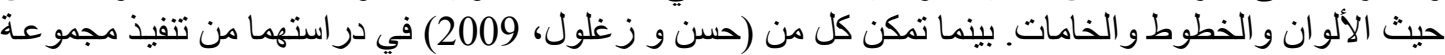

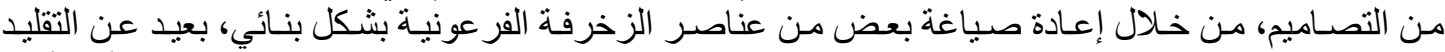

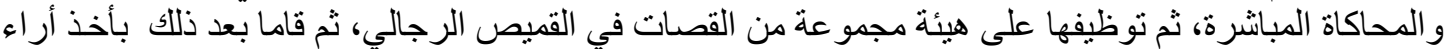

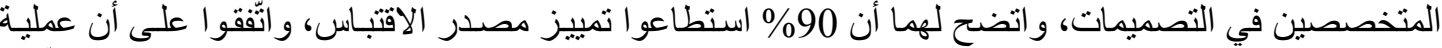
التحوير أضافت رؤية جديدة ومظهر ا مختلفا للتصاميم، وكذلك 97\% من و المستهلكين تقبلو ا هذه التصاميم، و أكّدوا

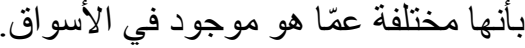

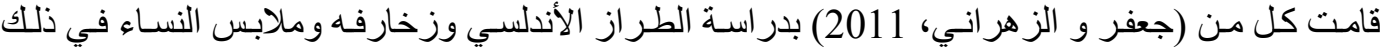

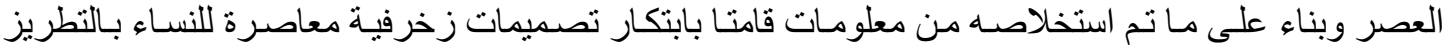

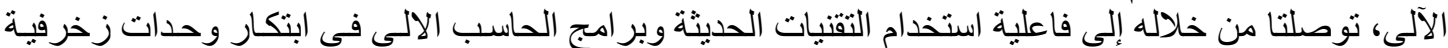




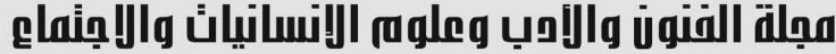 \\ Journal of Arts, Literature, Humanities and Social Sciences \\ www.jalhss.com}

\section{Volume (66) April 2021}

أبريل 2021

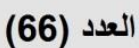

إسـلامية مقتبسـة مـن الطر از الأندلسـي. وكذلك أوصـتا بضـرورة در اسـة التراث و الفن الإسـلامي لأن ذلك يفتح

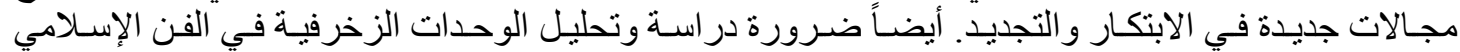

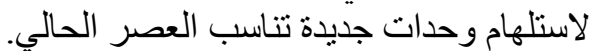

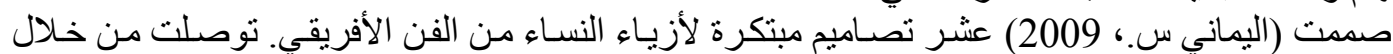

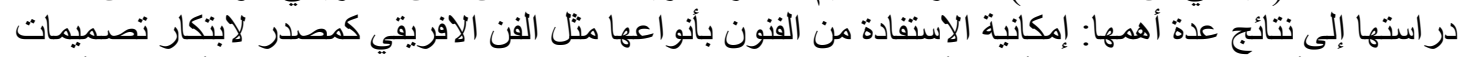

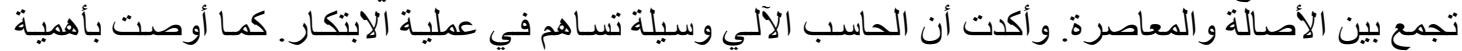

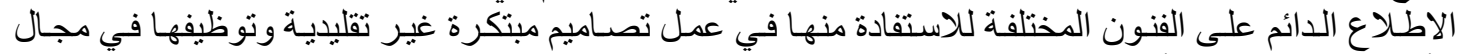
الأزياء حيث وضحت أن ذلك يساهم في الوصول إلى آفاق إبداعيـة متطورة تسـاعد على فتح مجـالات ابتكاريـة متعددة للمصممين.

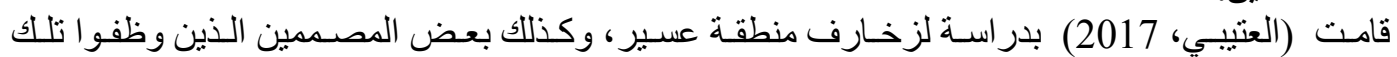

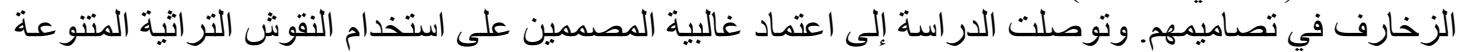

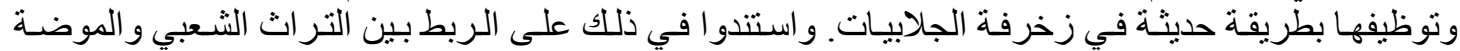

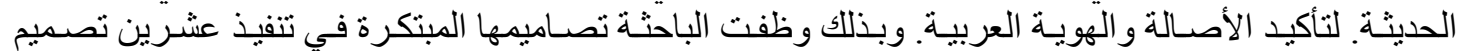

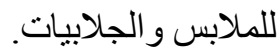

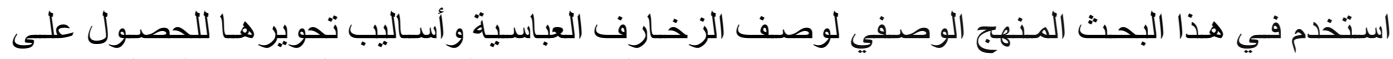
منهجية البحث:

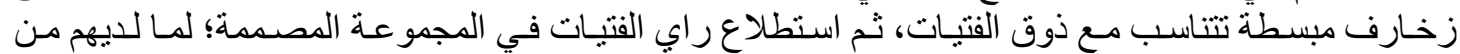

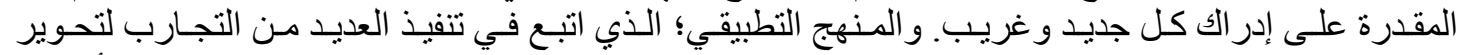
الزخارف العباسية، بطرق حديثة؛ للتمكن من استخدامها كوحدة زخرفية على التى العديد من القطع الملبسـة للأطفال. حيث أن التجريب بداية التعليم و اكتساب المهار ات، المبني على هدف يسبق التجربة ومخطط علمي يحدد مسار ها (اليماني، 2009).

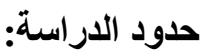

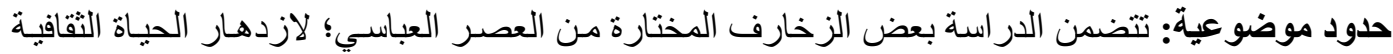

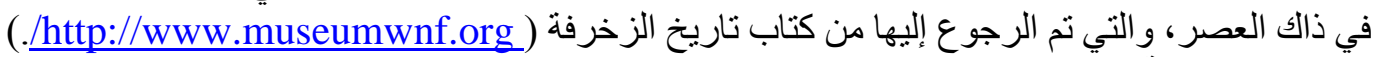
حدود زمانية: في الفصل الدر اسي الثناني للعام 1439-2018.

$$
\text { مجتمع البحًثة الإناث: من الأطفال في المملكة العربية السعودية. }
$$

\begin{tabular}{|c|c|c|}
\hline النسبة المئوية & التكرار & الخيارات \\
\hline$\% 21.0$ & 52 & 9 إلى > 10 \\
\hline$\% 30,6$ & 76 & 10 إلى > 11 \\
\hline$\% 21,8$ & 54 & 11 إلى > 12 \\
\hline$\% 26,6$ & 66 & 12 إلى > 13 \\
\hline$\% 100$ & 252 & المجموع \\
\hline
\end{tabular}

تكونت من عينه قصدية بو اقع 252 طفلة، من الفتيات من عمر 92 الى 12 سنة. جلول (1) توزيع أفراد العينة الاستطلاعية حسب الفئة العمرية

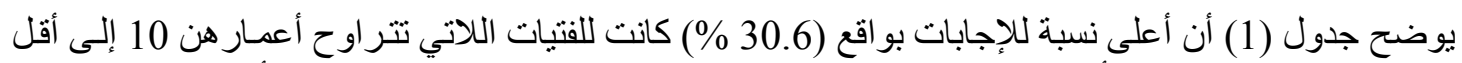

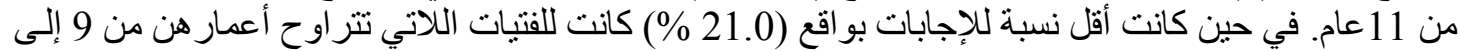

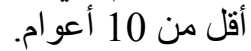




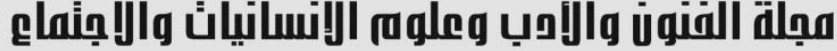

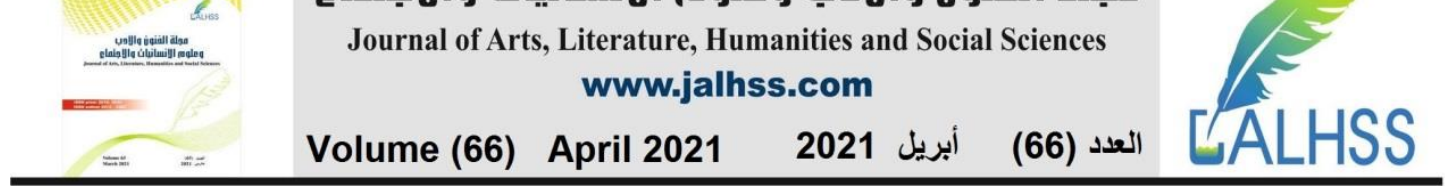

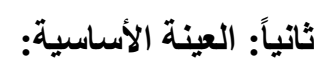
تكونت من عينة عشوائية بو اقع 428 طفلة، من الفتيات من عمر 9 الى 12 سنة.

\begin{tabular}{|c|c|c|}
\hline النسبة المئوية & التكرار & الخيارات \\
\hline$\% 15$ & 64 & 9 إلى > 10 \\
\hline$\% 12.1$ & 52 & 10 إلى > 11 \\
\hline$\% 10.5$ & 45 & 11 إلى > 12 \\
\hline$\% 62.4$ & 267 & 12 إلى > 13 \\
\hline$\% 100$ & 428 & المجموع \\
\hline
\end{tabular}

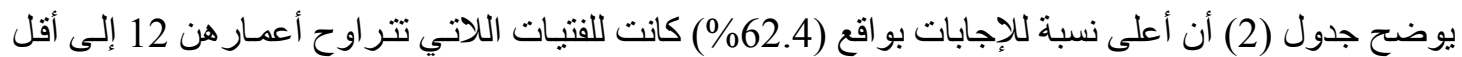

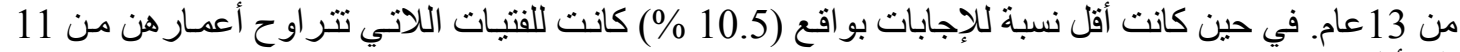

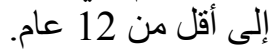

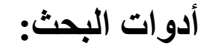

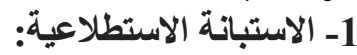

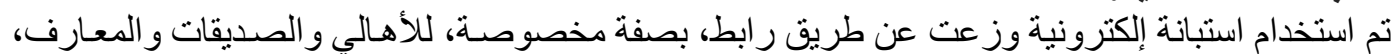

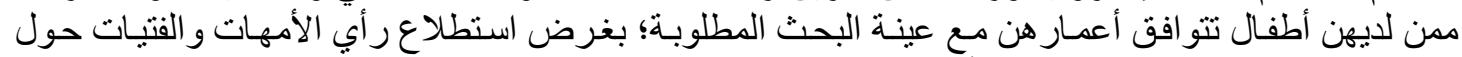

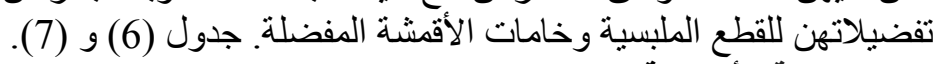

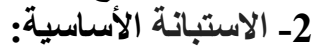
تم استخدام استبانة إلكترونية: لقياس رضـا أفر اد العينـة عن التصـاميم المقترحة، وبلغت عدد الاستجابات

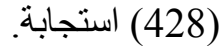

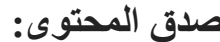

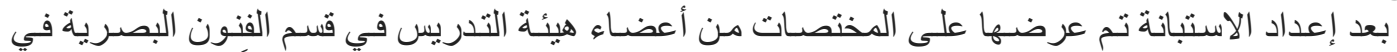

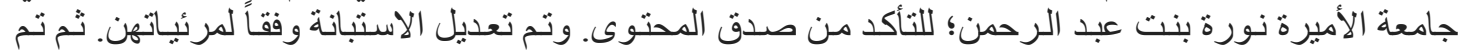

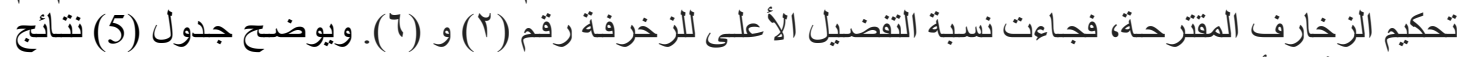

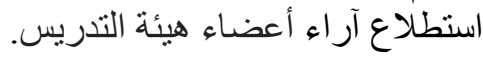
3-برنامج (Illustrator):

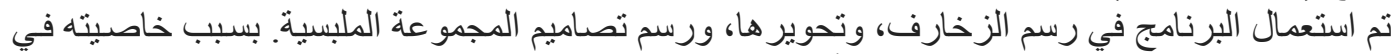
المحافظة على دقة الرسوم المنتجة، عند التكبير أو التصغير على فئ حد سواء.

$$
\text { الخطوات الإجرائية للبحث: }
$$

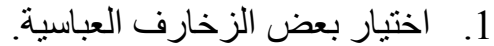

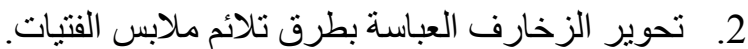

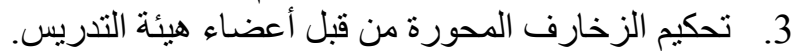

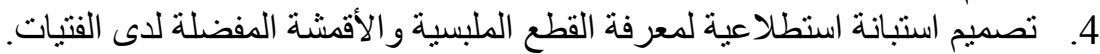

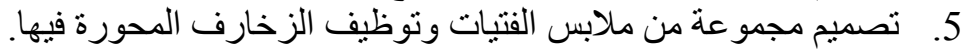

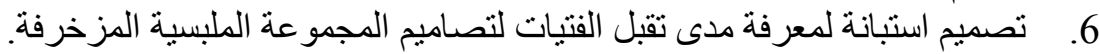
7. 


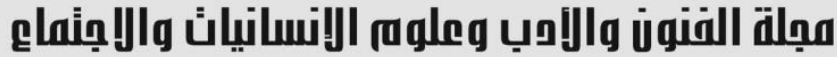

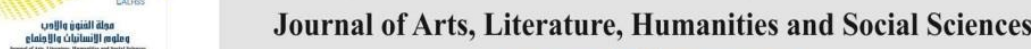
www.jalhss.com

\begin{tabular}{|c|c|c|c|c|c|c|}
\hline 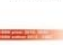 & & & www.jall & 5.com & & \\
\hline$=$ & $=$ & Volume (66) & April 2021 & أبريل 2021 & العدد (66) & 山 \\
\hline
\end{tabular}

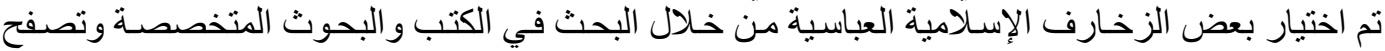

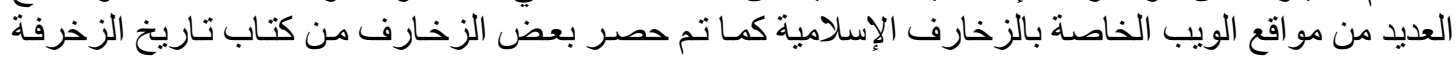

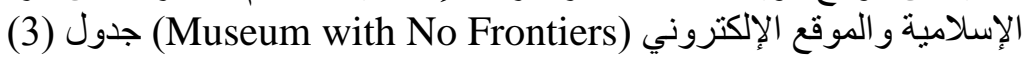

\section{جلول (3) بعض الزخارف العباسية التي سوف يتم الاقتباس منها}
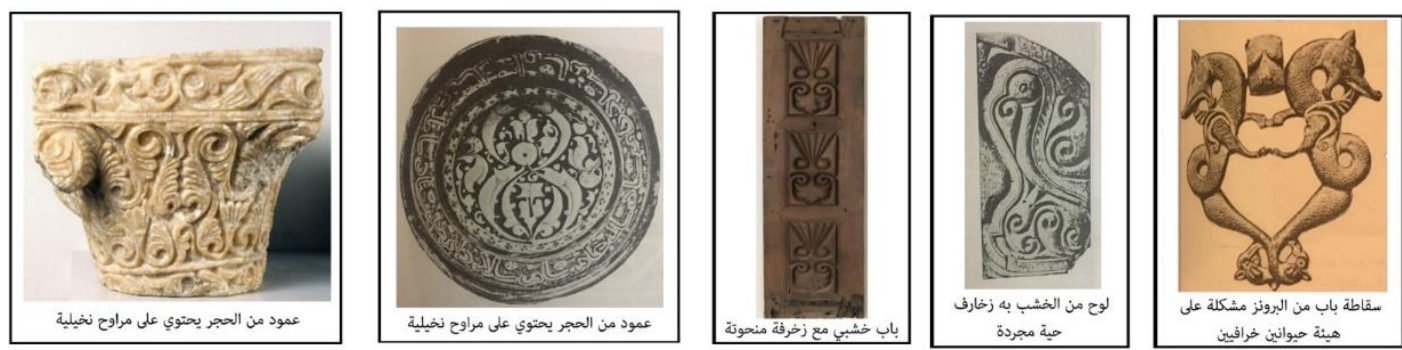

تحوير الزخرفة بما يتناسب مع ذوق الطقل:

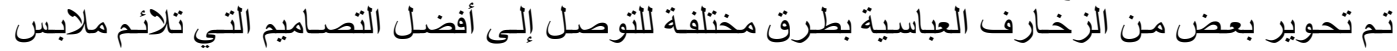
الفتيات. وقد اتبعت عدة طرق مثل الحذف والإضافة و إعادة الصياغة و غير ها من الطرق الموضحة في الجدول

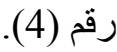




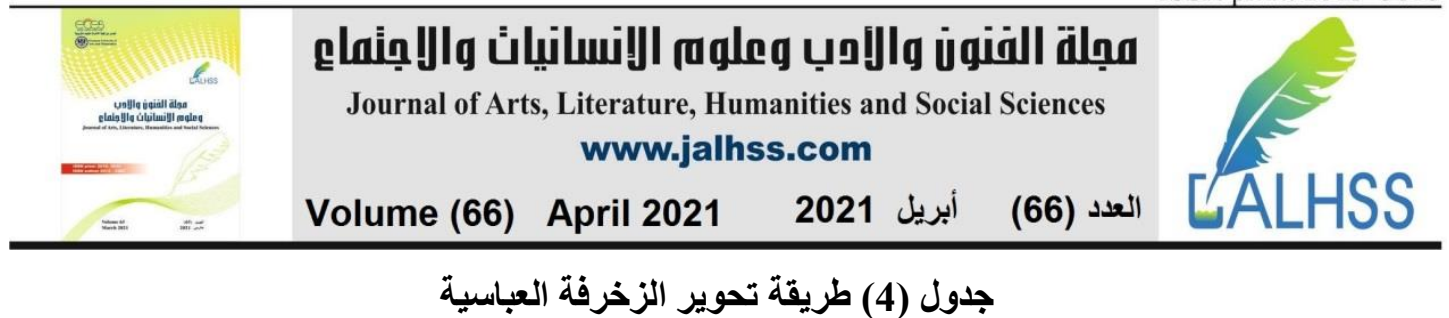

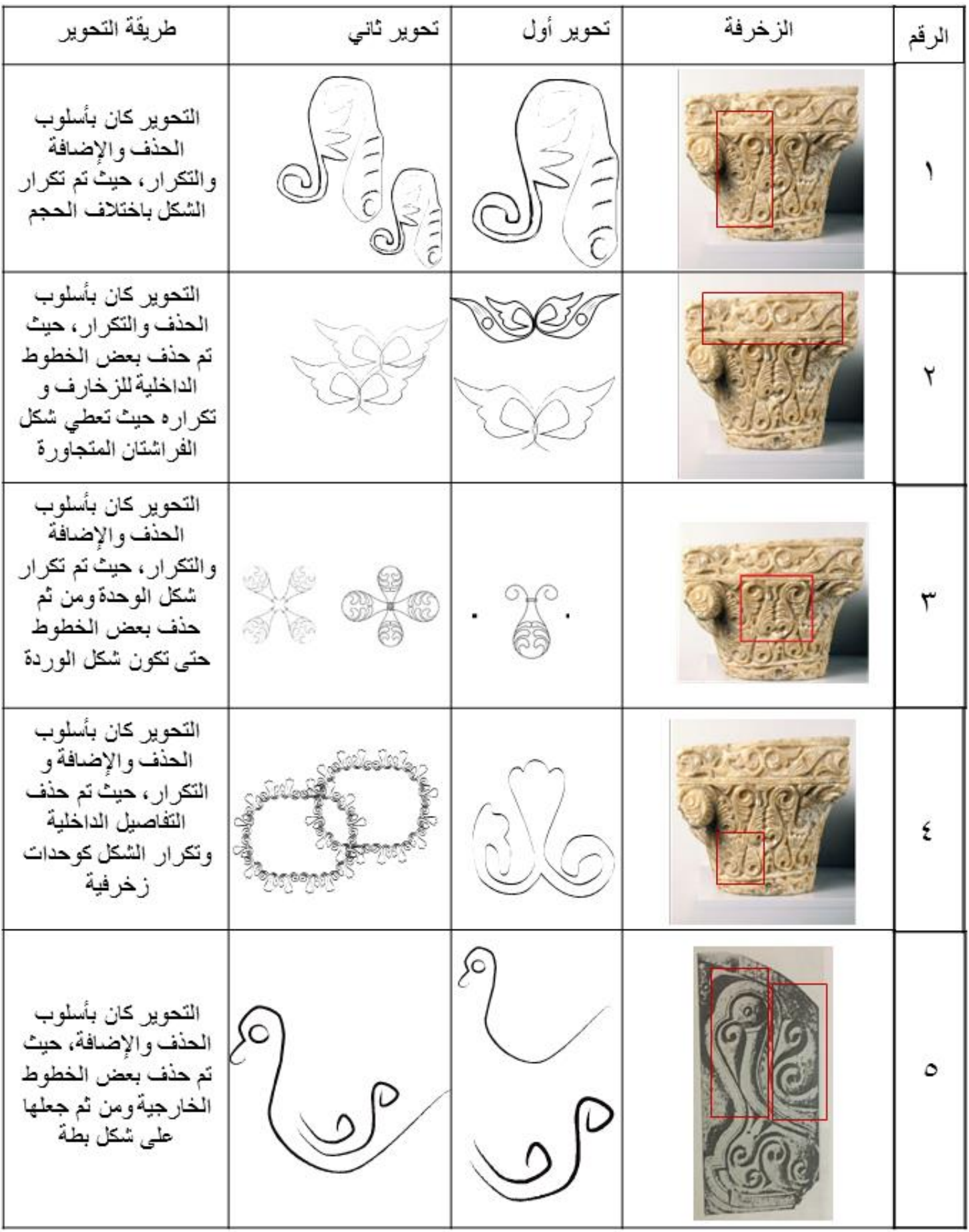




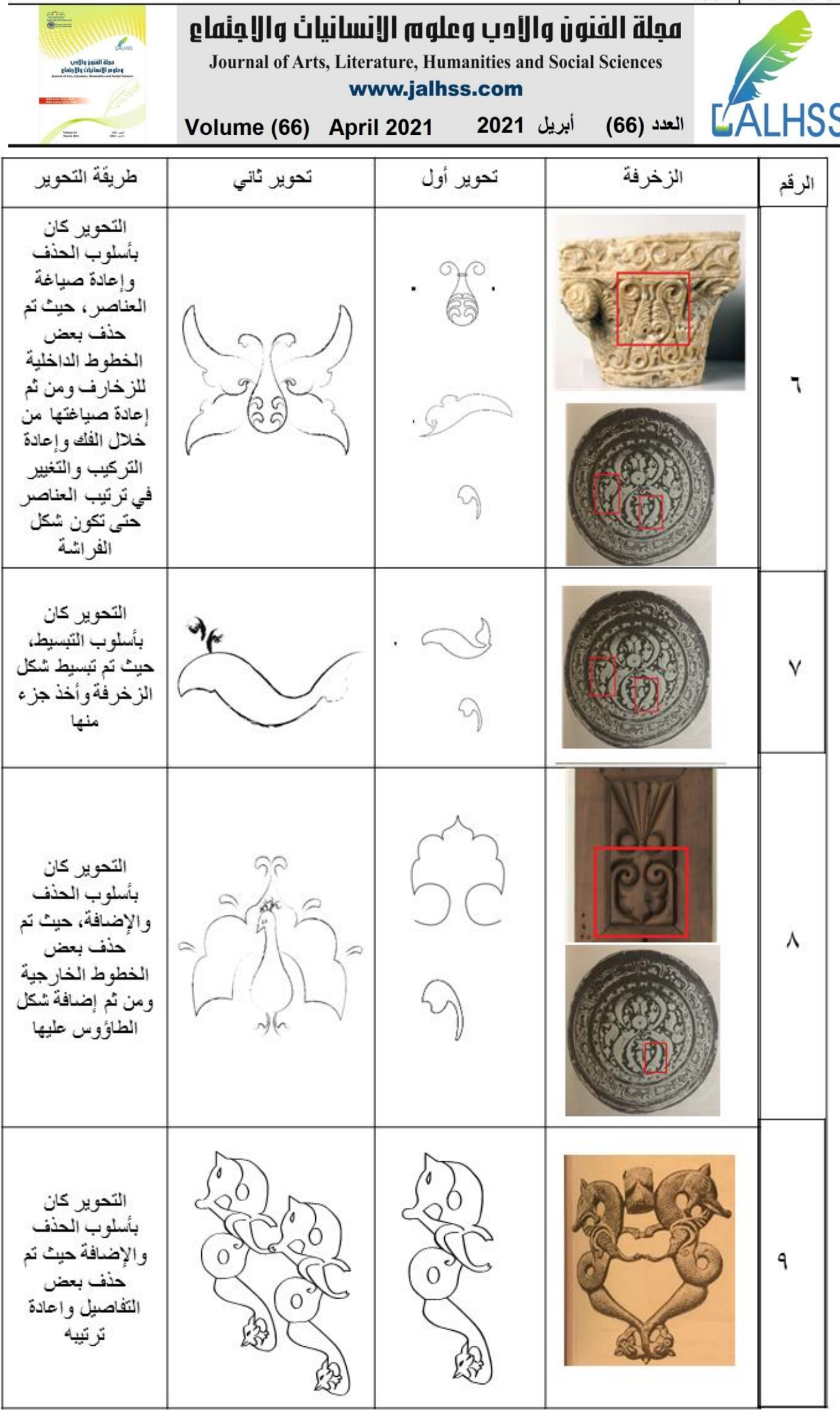




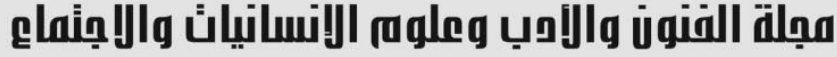

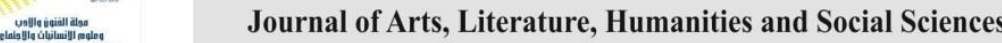

www.jalhss.com

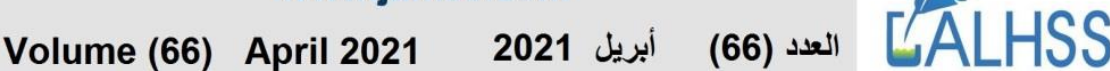

نتائج تحكيم تحوير الزخرفة من قبل الأعضاء المختصات في الفنون البصرية:

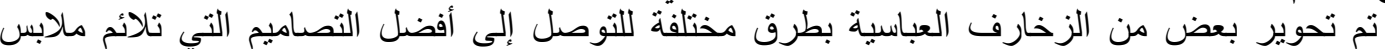

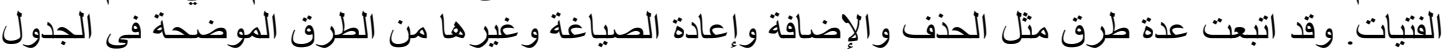

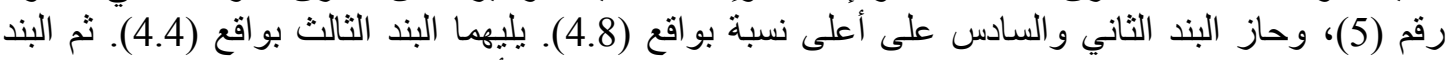

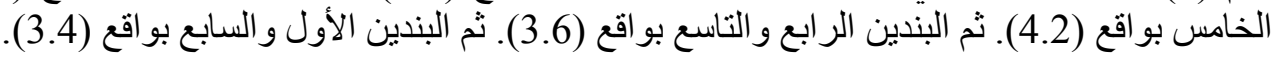

جدول (5) تحكيم الزخرفة المحورة من قبل أعضاء هيئة التدريس

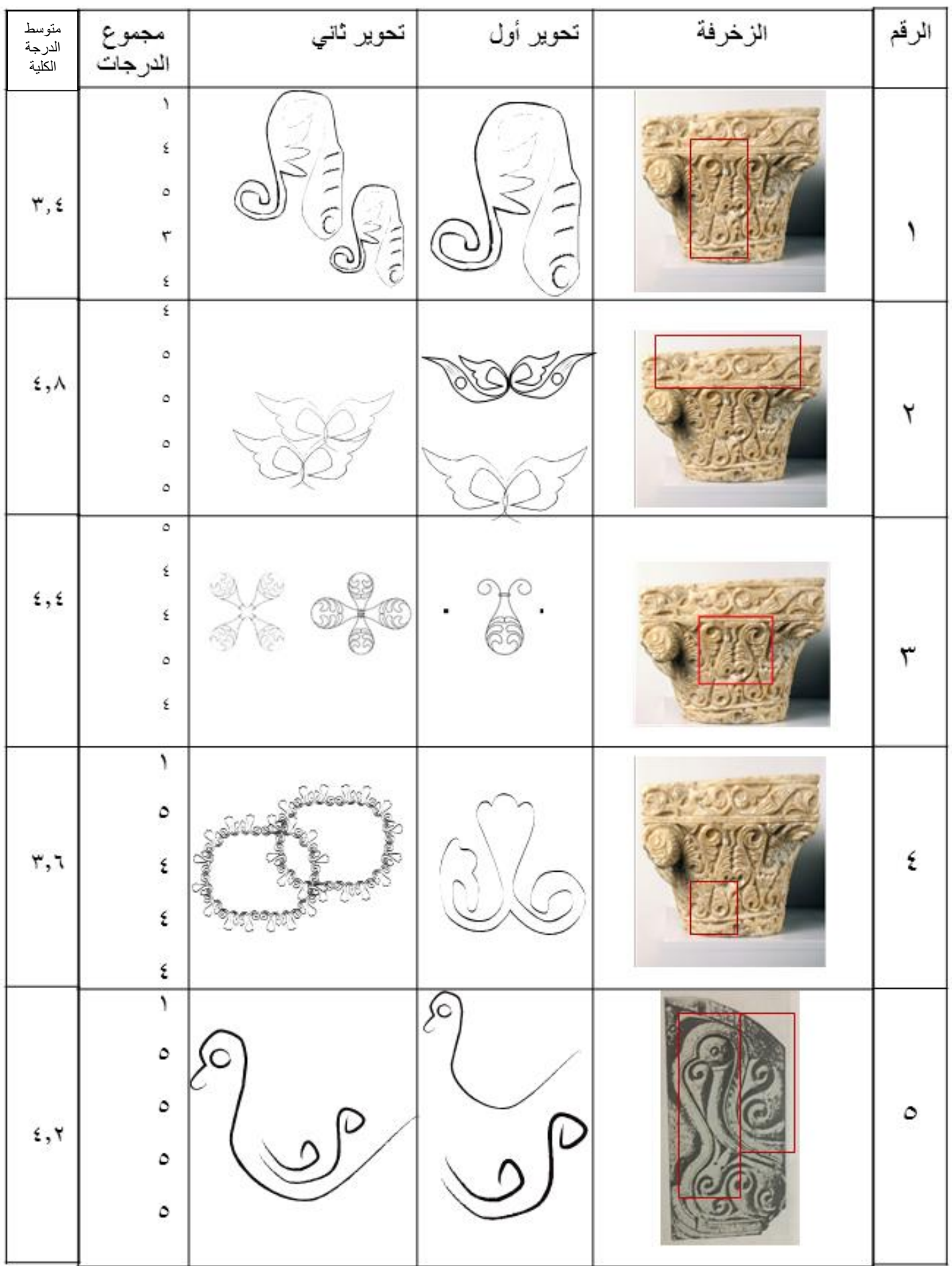




\begin{tabular}{|c|c|c|c|c|c|}
\hline 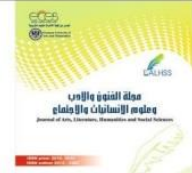 & $\begin{array}{c}\text { claing } \\
\text { Journal of Ar }\end{array}$ & $\begin{array}{l}\text { ts, Literature, Ht } \\
\text { www.jall }\end{array}$ & 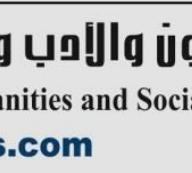 & în & \\
\hline$=\quad=$ & Volume (66) & April 2021 & أبريل 2021 & العدد (66) & \\
\hline
\end{tabular}

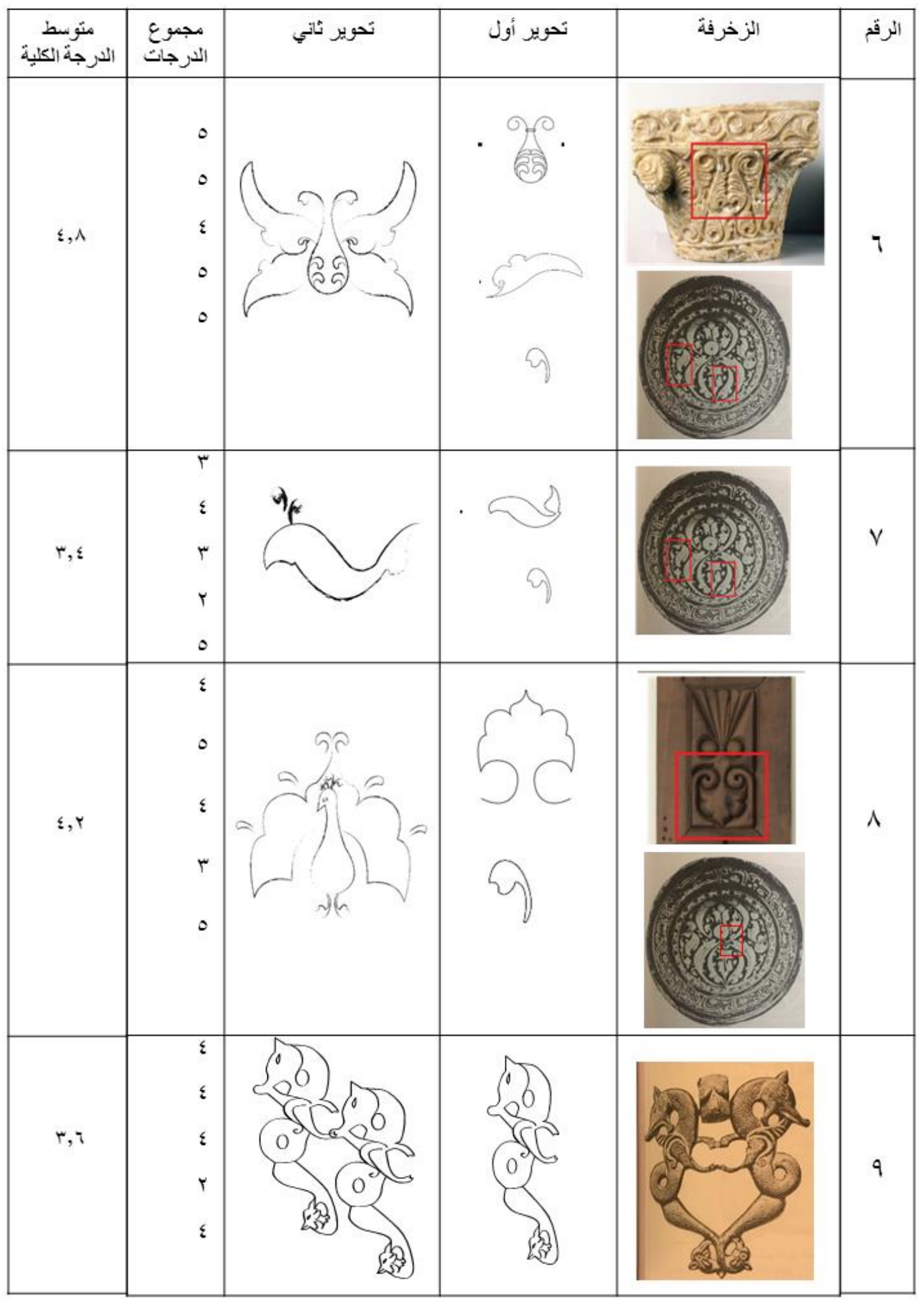




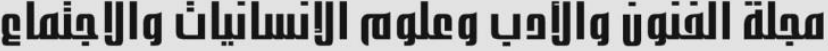

Journal of Arts, Literature, Humanities and Social Sciences www.jalhss.com

\section{Volume (66) April $2021 \quad$ أبريل 2021 أبدا 2021}

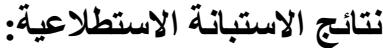

جدول (6) تفضيل أفراد العينة لأنواع القطع الملبسية المختلفة

\begin{tabular}{|c|c|c|}
\hline النسبة المئوية & التكرار & الخيارات \\
\hline$\% 17,5$ & 44 & جاكيت \\
\hline$\% 19.0$ & 48 & تنوره \\
\hline$\% 13,1$ & 33 & بنطلون \\
\hline$\% 12,7$ & 32 & بلوزه \\
\hline$\% 35,7$ & 90 & فستان \\
\hline$\% 2.0$ & 5 & غير ذلك \\
\hline$\% 100$ & 252 & المجموع \\
\hline
\end{tabular}

يوضح جدول (6) أن أعلى نسبة تفضيل للفستان بو اقع (35.7 \% \%)، بينما أقل نسبة كانت للبلوزة بو اقع (12.7 \%)، أما نسبة (2.0 \% \%) كانت لأنو اع مختلفة من القطع الأخرى.

\section{جلول (7) تفضيل أفراد العينة لأنواع الأقمشة المختلفة}

\begin{tabular}{|c|c|c|}
\hline النسبة المئوية & التكرار & التفضيلات في أنواع الأقمشة \\
\hline$\% 29$ & 73 & جينز \\
\hline$\% 8,7$ & 22 & جلد \\
\hline$\% 58,7$ & 148 & قطن \\
\hline$\% 3,6$ & 8 & غير ذللك \\
\hline$\% 100$ & 252 & المجموع \\
\hline
\end{tabular}

يوضح جدول (7) أن أعلى نسبة كانت لقماش القطن بو اقع (58,7\%)، بينما أقل نسبة كانت لأنواع مختلفة من الأقشة بو اقع (8.7 \% (7).

نتائج الاستبانة الأساسية:

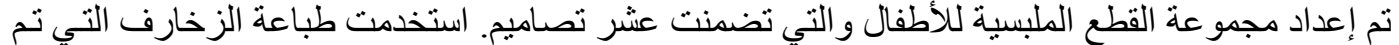

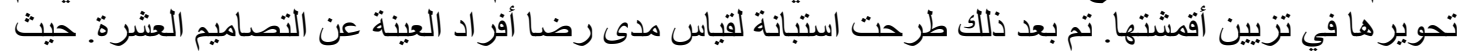

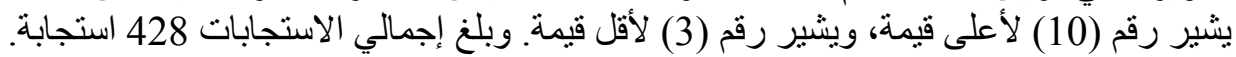

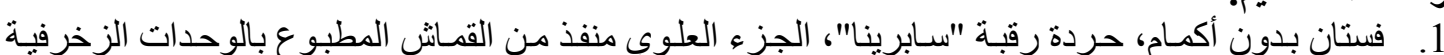

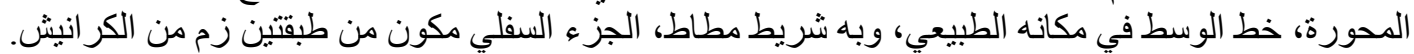

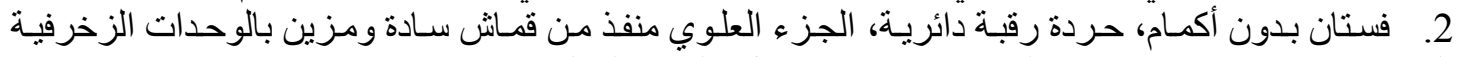

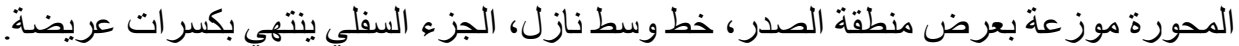

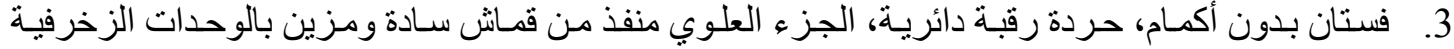

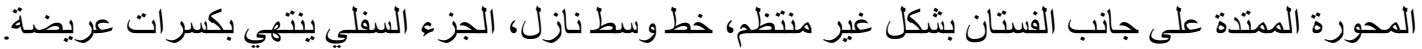

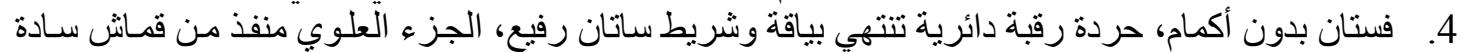

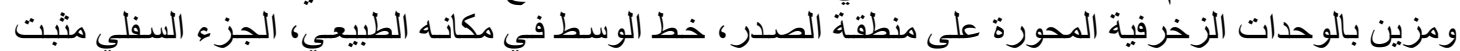
بكسر ات عريضة عوضاً عن الزم، طرفه مزين بالوحدات الزخرفية المحورة. 


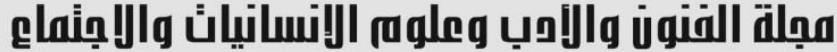

vallo inialat then

Journal of Arts, Literature, Humanities and Social Sciences

www.jalhss.com

\section{Volume (66) April 2021}

2021 أبريل

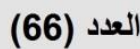

LALHSS

5. فستان على شكل أنبوبي، بدون وسط، لـه أكسام قصبرة، حردة رقبـة دائريـة، منفذ من القماش المطبوع بالوحدات الزخرفية المحورة.

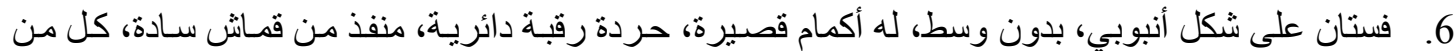

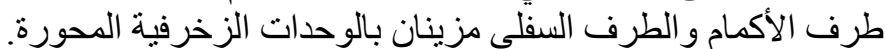

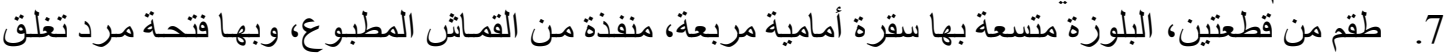

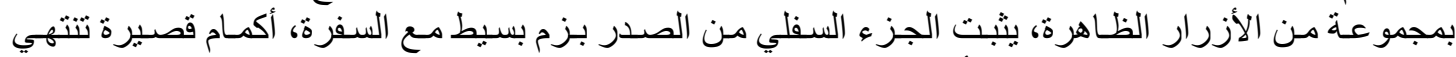

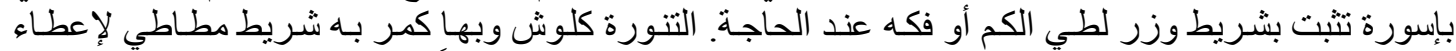

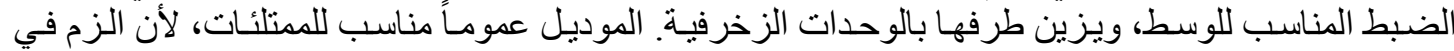
السفرة يخفي الامتلاء في منطقة البطن.

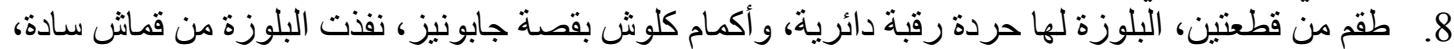

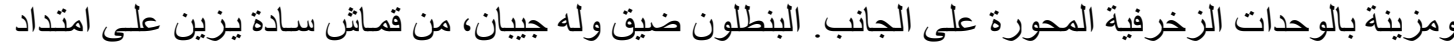

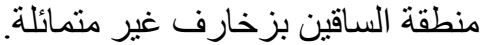

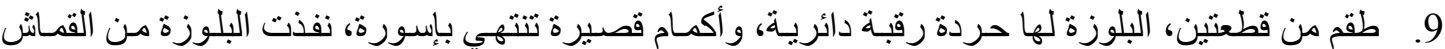

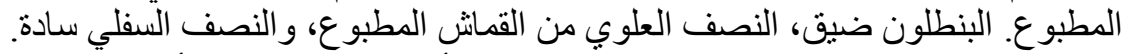

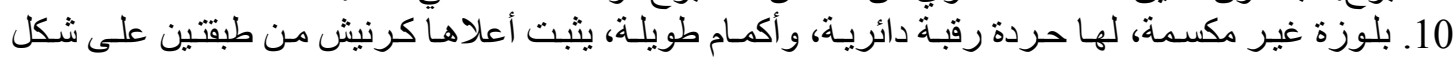
جابونيز، منفذة من القماش المطبوع.

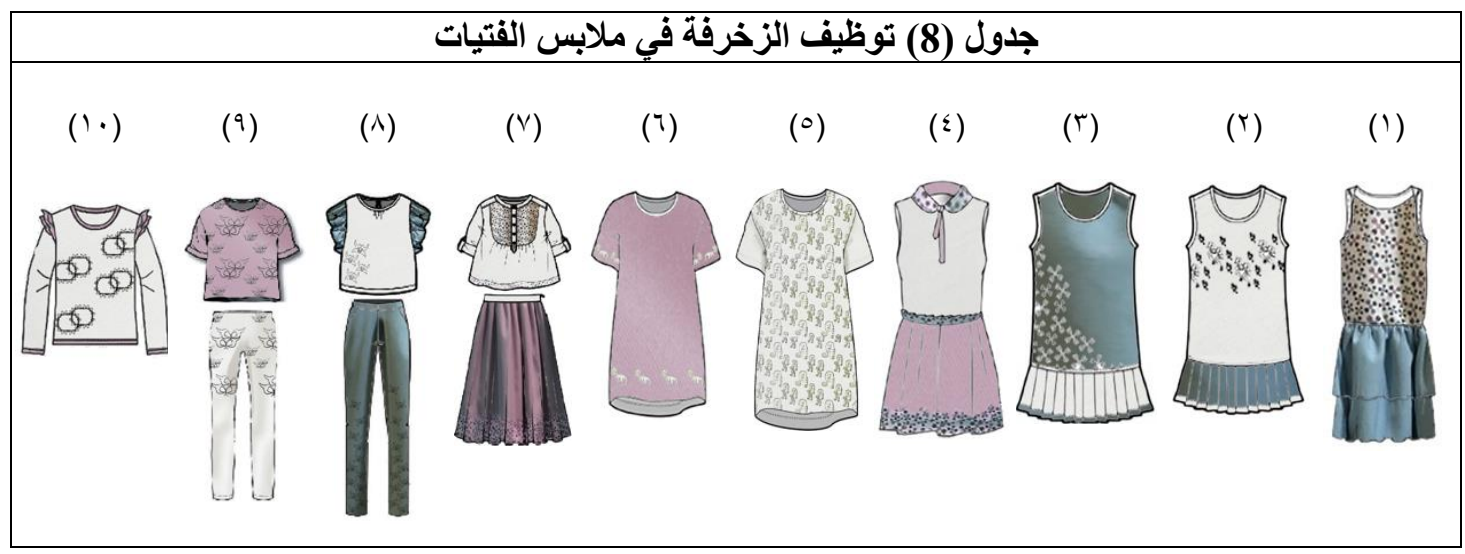

جدول (9) تقييم أفراد العينة لجمالية التصميم الأول

\begin{tabular}{|c|c|c|c|c|}
\hline \multicolumn{2}{|r|}{ النسبة } & التكرار & التقييم & \multirow{2}{*}{ لتصميم (الأول) } \\
\hline \multicolumn{2}{|r|}{$\% 9.8$} & 42 & 1 & \\
\hline \multicolumn{2}{|r|}{$\% 10.7$} & 46 & 2 & \\
\hline \multicolumn{2}{|r|}{$\% 16.6$} & 71 & 3 & \\
\hline \multicolumn{2}{|r|}{$\% 12,6$} & 54 & 4 & \\
\hline \multicolumn{2}{|r|}{$\% 50.2$} & 215 & 5 & \\
\hline$\% 100$ & المجموع & 428 & الهجموع & \\
\hline $21.8 \%$ & متوسط النسب المئوية & & & \\
\hline الثاني & التزتيب & & & \\
\hline
\end{tabular}




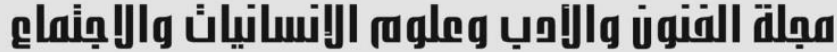 \\ Journal of Arts, Literature, Humanities and Social Sciences www.jalhss.com}

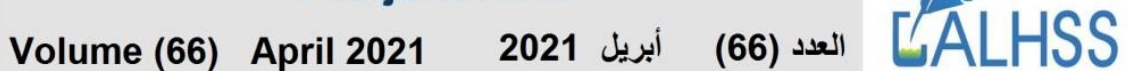

يوضح جدول (9) أن أعلى نسبة تقيم بو اقع (50.2\%) للتصميم الأول كانت للقيمة (5) في حين أن أقل نسبة تقييم بو اقع (9.8 \% \%) كانت للقيمة (1).

جدول (10) تقييم أفراد العينة لجمالية التصميم الثاني

\begin{tabular}{|c|c|c|c|c|}
\hline \multicolumn{2}{|r|}{ النسبة } & التكر ار & التقييم & \multirow[t]{2}{*}{ التصميم (الثاني) } \\
\hline \multicolumn{2}{|r|}{$\% 11,9$} & 51 & 1 & \\
\hline \multicolumn{2}{|r|}{$\% 10.3$} & 44 & 2 & \multirow{5}{*}{$\left|\begin{array}{lll}-2 & 8 \cdot 2\end{array}\right|$} \\
\hline \multicolumn{2}{|r|}{$\% 26.6$} & 114 & 3 & \\
\hline \multicolumn{2}{|r|}{$\% 27,6$} & 118 & 4 & \\
\hline \multicolumn{2}{|r|}{$\% 23,6$} & 101 & 5 & \\
\hline$\% 100$ & المجموع & \multirow[t]{3}{*}{428} & \multirow[t]{3}{*}{ المجموع } & \\
\hline$\% 18.5$ & متوسط النسب المئوية & & & \\
\hline الخامس & الترتيب & & & \\
\hline
\end{tabular}

يو بـح جدول (10) أن أعلى نسبة تقييم بواقع (27.7\%) للتصميم الثاني كانت للقيمة (4) في حين أن أقل نسبة

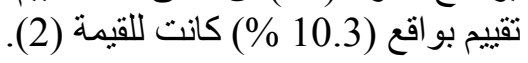

جدول (11) تقييم أفراد العينة لجمالية التصميم الثالث

\begin{tabular}{|c|c|c|c|c|}
\hline \multicolumn{2}{|r|}{ النسبة } & التكر ار & التقبيم & \multirow[t]{2}{*}{ لتصميم (الثالث) } \\
\hline \multicolumn{2}{|r|}{$\% 9,6$} & 41 & 1 & \\
\hline \multicolumn{2}{|r|}{$\% 7,7$} & 33 & 2 & \multirow{7}{*}{ F } \\
\hline \multicolumn{2}{|r|}{$\% 20,1$} & 86 & 3 & \\
\hline \multicolumn{2}{|r|}{$\% 35,7$} & 153 & 4 & \\
\hline \multicolumn{2}{|r|}{$\% 26,9$} & 115 & 5 & \\
\hline$\% 100$ & المجموع & \multirow[t]{3}{*}{428} & \multirow[t]{3}{*}{ المجموع } & \\
\hline$\% 12.5$ & منوسط النسب المئوية & & & \\
\hline السابع & الترتيب & & & \\
\hline
\end{tabular}

يوضح جدول (11) أن أعلى نسبة تقييم بو اقع (35,7\%) للتصميم الثالث كانت للقيمة (4) في حين أن أقل نسبة تقييم بو اقع (7,7 \% \% (11) كانت ألقيمة (2). 


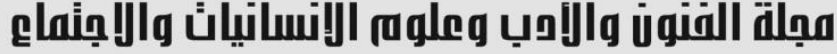

Journal of Arts, Literature, Humanities and Social Sciences www.jalhss.com

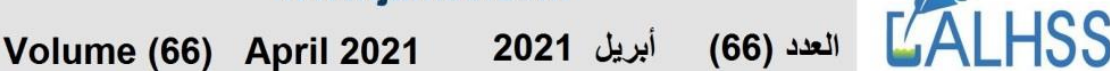

جدول (12) تقييم أفراد العينة لجمالية التصميم الرابع

\begin{tabular}{|c|c|c|c|c|}
\hline \multicolumn{2}{|r|}{ النسبة } & التكرار & التقبيم & \multirow{2}{*}{ التصميم (الر ابع) } \\
\hline \multicolumn{2}{|r|}{$\% 7,2$} & 31 & 1 & \\
\hline \multicolumn{2}{|r|}{$\% 6,1$} & 26 & 2 & \multirow[b]{5}{*}{ proppers } \\
\hline \multicolumn{2}{|r|}{$\% 15$} & 64 & 3 & \\
\hline \multicolumn{2}{|r|}{$\% 34,3$} & 147 & 4 & \\
\hline \multicolumn{2}{|r|}{$\% 37,4$} & 160 & 5 & \\
\hline$\% 100$ & المجموع & \multirow[t]{3}{*}{428} & \multirow[t]{3}{*}{ المجموع } & \\
\hline$\% 15.0$ & منوسط النسب المئوية & & & \\
\hline السادس & الترتيب & & & \\
\hline
\end{tabular}

يوضح جدول (12) أن أعلى نسبة تقييم بو اقع (37,4\%) للتصميم الر ابع كانت للقيمة (5) في حين أن أقل نسبة

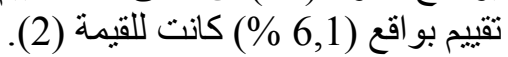

جدول (13) تقييم أفراد العينة لجمالية التصميم الخامس

\begin{tabular}{|c|c|c|c|c|}
\hline \multicolumn{2}{|r|}{ النسبة } & التكرار & التقبيم & \multirow[t]{2}{*}{ التصميم (الخامس) } \\
\hline \multicolumn{2}{|r|}{$\% 7,5$} & 32 & 1 & \\
\hline \multicolumn{2}{|r|}{$\% 8,6$} & 37 & 2 & \\
\hline \multicolumn{2}{|r|}{$\% 12,4$} & 53 & 3 & \\
\hline \multicolumn{2}{|r|}{$\% 19,4$} & 83 & 4 & \\
\hline \multicolumn{2}{|r|}{$\% 52,1$} & 223 & 5 & \\
\hline$\% 100$ & المجموع & 428 & المجموع & \\
\hline$\% 20.0$ & متوسط النسب المئوية & & & \\
\hline الثالث & الترتيب & & & \\
\hline
\end{tabular}

يوضح جدول (13) أن أعلى نسبة تقييم بو اقع (52,1\%) للتصميم الخامس كانت للقيمة (5) في حين أن أقل نسبة تقييم بو اقع (7,5 \%) كانت للقيمة (1) (13). 


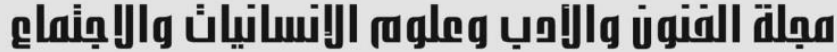

Journal of Arts, Literature, Humanities and Social Sciences www.jalhss.com

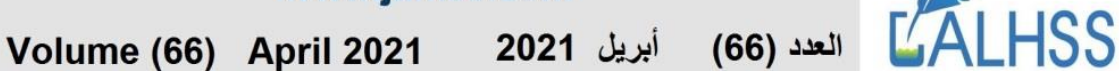

جدول (14) تقييم أفراد العينة لجمالية التصميم السادس

\begin{tabular}{|c|c|c|c|c|}
\hline & النسبة & التكر ار & التقبيم & التصميم (السادس) \\
\hline & $\% 7,5$ & 32 & 1 & \\
\hline & $\% 7,5$ & 32 & 2 & \\
\hline & $\% 13,1$ & 56 & 3 & \\
\hline & $\% 34,8$ & 149 & 4 & \\
\hline & $\% 37,1$ & 159 & 5 & \\
\hline$\% 100$ & المجموع & 428 & المجموع & \\
\hline$\% 20.0$ & متوسط النسب المئوية & & & \\
\hline الثالث م & الترتيب & & & \\
\hline
\end{tabular}

يوضح جدول (14) أن أعلى نسبة تقييم بو اقع (37,1\%) للتصميم السادس كانت للقيمة (5) في حين أن أقل نسبة

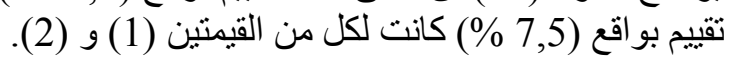

جدول (15) تقييم أفراد العينة لجمالية التصميم السابع

\begin{tabular}{|c|c|c|c|c|}
\hline \multicolumn{2}{|r|}{ النسبة } & التكرار & التقييم & \multirow[t]{2}{*}{ التصميم (السابع) } \\
\hline \multicolumn{2}{|r|}{$\% 14.0$} & 60 & 1 & \\
\hline \multicolumn{2}{|r|}{$\% 10.0$} & 43 & 2 & \\
\hline \multicolumn{2}{|r|}{$\% 13,8$} & 59 & 3 & \\
\hline \multicolumn{2}{|r|}{$\% 32.0$} & 137 & 4 & \\
\hline \multicolumn{2}{|r|}{$\% 30,1$} & 129 & 5 & \\
\hline$\% 100$ & المجموع & 428 & المجموع & \\
\hline $18.7 \%$ & منوسط النسب المئوية & & & \\
\hline الر ابع & الترتيب & & & \\
\hline
\end{tabular}

يو بـح جدول (15) أن أعلى نسبة تقييم بو اقع (32.0\%) للتصميم السابع كانت للقيمة (4) في حين أن أقل نسبة

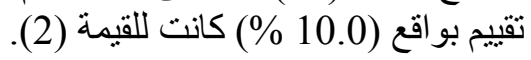




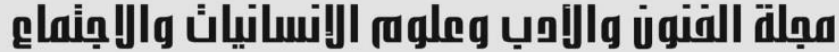

Journal of Arts, Literature, Humanities and Social Sciences www.jalhss.com

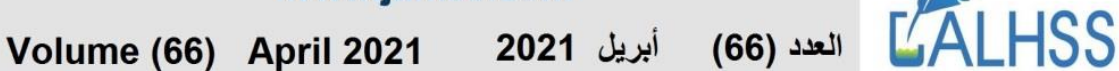

جدول (16) تقييم أفراد العينة لجمالية التصميم الثامن

\begin{tabular}{|c|c|c|c|c|}
\hline & النسبة & التكرار & التقبيم & التصميم (الثامن) \\
\hline & $\% 11,9$ & 51 & 1 & \\
\hline & $\% 7,5$ & 32 & 2 & \\
\hline & $\% 14,7$ & 63 & 3 & \\
\hline & $\% 33,4$ & 143 & 4 & \\
\hline & $\% 32,5$ & 139 & 5 & \\
\hline$\% 100$ & المجموع & 428 & المجموع & \\
\hline $20.0 \%$ & متوسط النسب المئوية & & & \\
\hline الثالث م & الترتيب & & & \\
\hline
\end{tabular}

يوضح جدول (16) أن أعلى نسبة تقييم بو اقع (33,4\%) للتصميم الثامن كانت للقيمة (4) في حين أن أقل نسبة

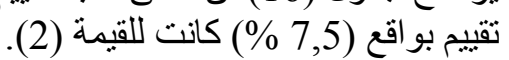

جدول (17) تقييم أفراد العينة لجمالية التصميم التاسع

\begin{tabular}{|c|c|c|c|c|}
\hline \multicolumn{2}{|r|}{ النسبة } & التكر ار & التقييم & \multirow[t]{2}{*}{ التصميم (التاسع) } \\
\hline \multicolumn{2}{|r|}{$\% 11,7$} & 50 & 1 & \\
\hline \multicolumn{2}{|r|}{$\% 9,1$} & 39 & 2 & \multirow{5}{*}{ एक } \\
\hline \multicolumn{2}{|r|}{$\% 27,3$} & 117 & 3 & \\
\hline \multicolumn{2}{|r|}{$\% 25,9$} & 111 & 4 & \\
\hline \multicolumn{2}{|r|}{$\% 25,9$} & 111 & 5 & \\
\hline$\% 100$ & المجموع & 428 & المجموع & \\
\hline $18.5 \%$ & متوسط النسب المئوية & & & \\
\hline لخامس م & الترتيب & & & DU \\
\hline
\end{tabular}

يوضح جدول (17) أن أعلى نسبة تقييم بو اقع (27,3\%) للتصميم التاسع كانت للقيمة (3) في حين أن أقل نسبة تقييم بو اقع (9,1 \% \%) كانت للقيمة (2) (17). 


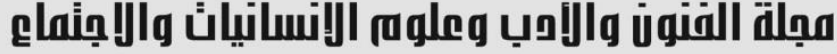

Journal of Arts, Literature, Humanities and Social Sciences

www.jalhss.com

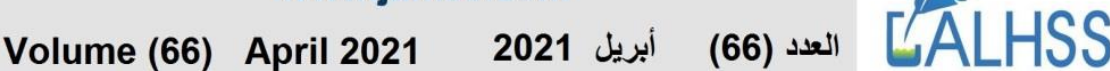

\section{جدول (18) تقييم أفراد العينة لجمالية التصميم العاشر}

\begin{tabular}{|c|c|c|c|c|}
\hline \multicolumn{2}{|r|}{ النسبة } & التكرار & التقبيم & التصميم (العاثر ) \\
\hline \multicolumn{2}{|r|}{$\% 13,1$} & 56 & 1 & \\
\hline \multicolumn{2}{|r|}{$\% 12,6$} & 54 & 2 & \\
\hline \multicolumn{2}{|r|}{$\% 23,8$} & 102 & 3 & \\
\hline \multicolumn{2}{|r|}{$\% 28.0$} & 120 & 4 & \\
\hline \multicolumn{2}{|r|}{$\% 22,4$} & 96 & 5 & \\
\hline$\% 100$ & المجموع & 428 & المجموع & \\
\hline $28.0 \%$ & منوسط النسب المئوية & & & \\
\hline الأول & الترتيب & & & \\
\hline
\end{tabular}

يوضح جدول (18) أن أعلى نسبة تقييم بو اقع (28.0\%) للتصميم العاشر كانت للقيمة (4) في حين أن أقل نسبة

تقييم بو اقع (12,6\%) كانت للقيمة (2).

\section{جدول (19) المتوسطات الحسابية لجميع التصاميم العشرة}

\begin{tabular}{|c|c|c|c|c|c|c|c|c|c|c|}
\hline 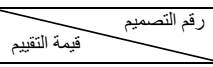 & الأول & الثاني & الثالث & الر ابع & الخامس & السادس & السابع & الثامن & التاسع & العاشر \\
\hline 1 & 9.80 & 11,9 & 9.60 & 7,2 & 7.50 & 7.50 & 14.00 & 11.90 & 11.70 & 13,1 \\
\hline 2 & 10.70 & 10.30 & 7.70 & 6,1 & 8.60 & 7.50 & 10.00 & 7.50 & 9.10 & 12,6 \\
\hline 3 & 16.60 & 26.60 & 20.10 & 15 & 12.40 & 13.10 & 13,8 & 14.70 & 27.30 & 23,8 \\
\hline 4 & 12,6 & 27,6 & 35,7 & 34,3 & 19.40 & 34.80 & 32.00 & 33.40 & 25.90 & 28.00 \\
\hline 5 & 50.20 & 23,6 & 26,9 & 37,4 & 52.10 & 37.10 & 30,1 & 32.50 & 25,9 & 22,4 \\
\hline متوسط المتوسطات & $21.8 \%$ & $18.5 \%$ & $12.5 \%$ & $15.0 \%$ & $20.0 \%$ & $20.0 \%$ & $18.7 \%$ & $20.0 \%$ & $18.5 \%$ & $28.0 \%$ \\
\hline التزتيب & 2 & 5 & 7 & 6 & 3 & 3 & 4 & 3 & 5 & 1 \\
\hline
\end{tabular}




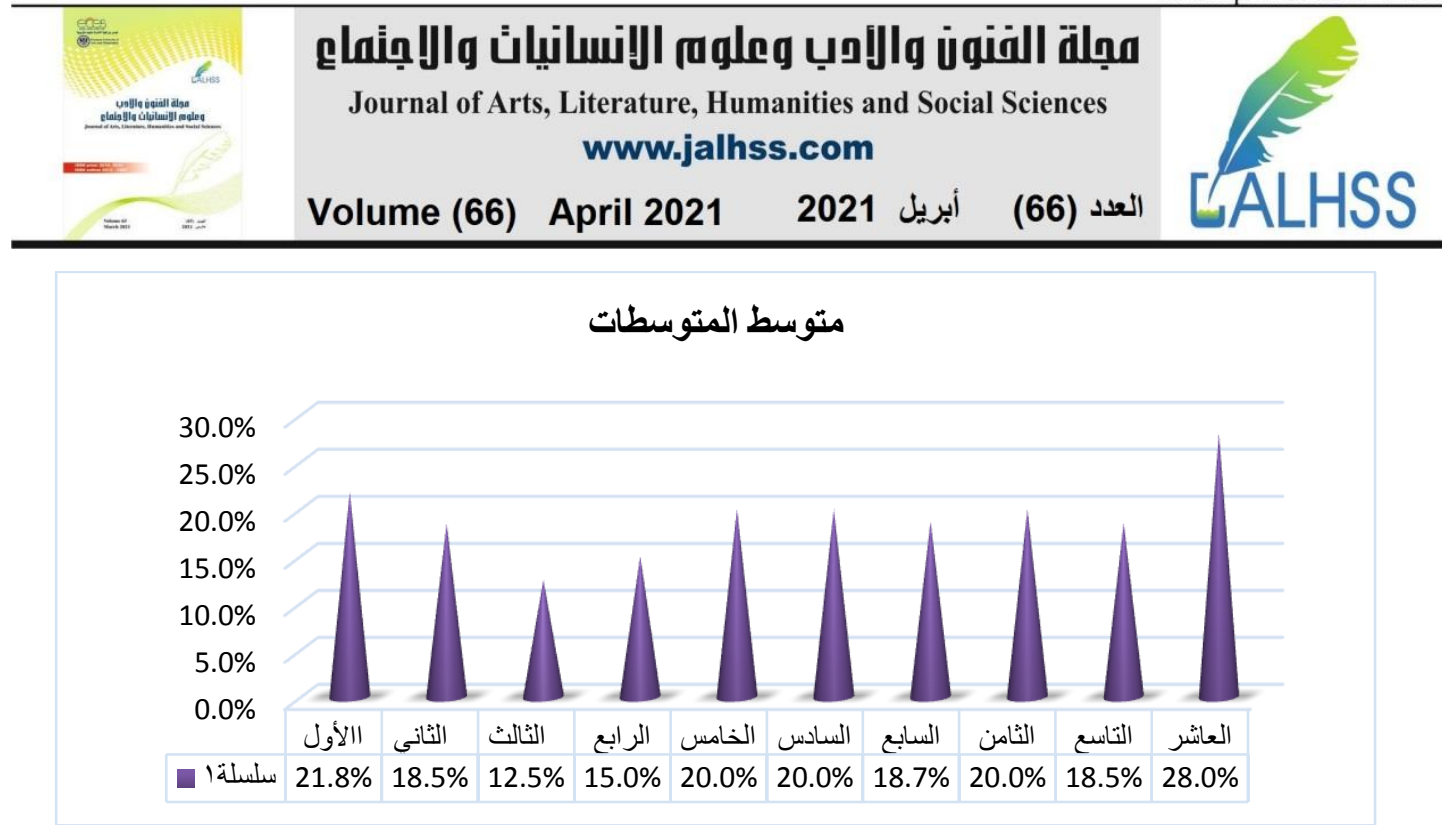
اتضـح من النتائج: إمكانيـة تحوير الزخـارف العباسية بمـا يتناسب مـع اختلاف أذواق الفتيات. حيث تم ترتيب

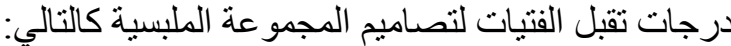

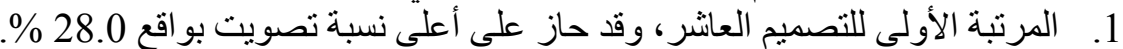

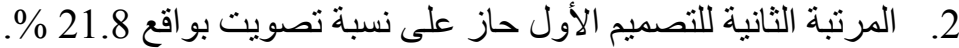

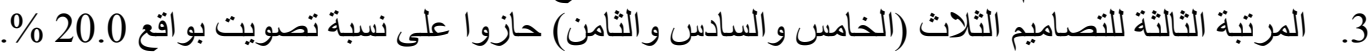

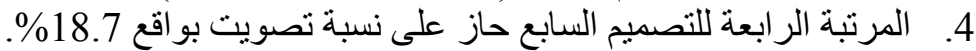

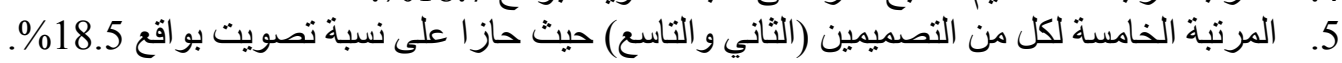

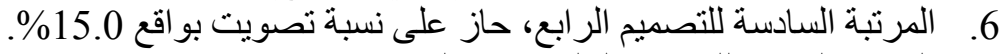
7. المرتبة السابعة للتصميم الثالث حاز على نسبة تصويت بواقع 12.5\%

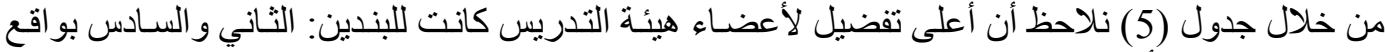

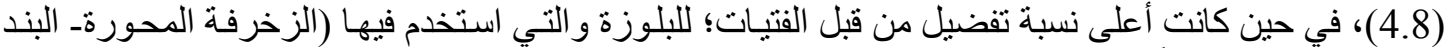

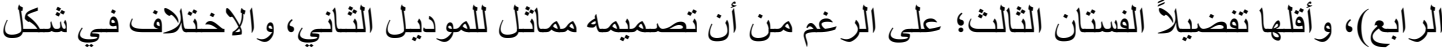

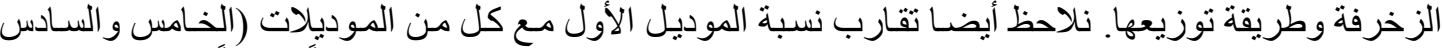

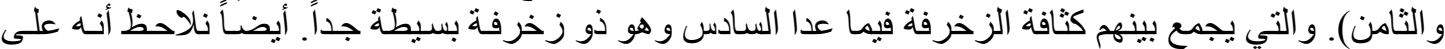

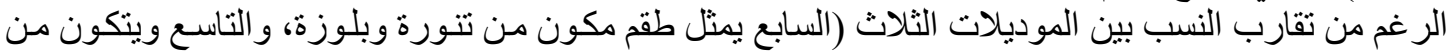

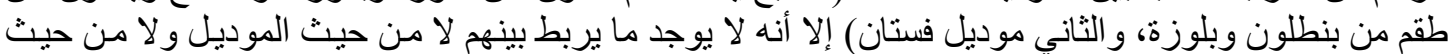
شكل الزخرفة أو كثافتها أو طريقة نوزيعها.

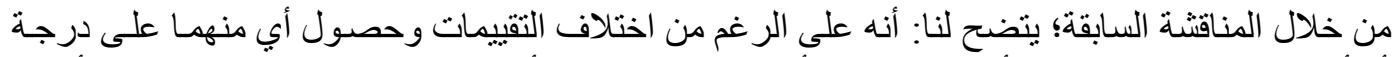

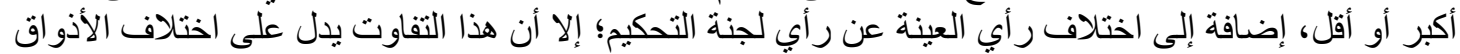

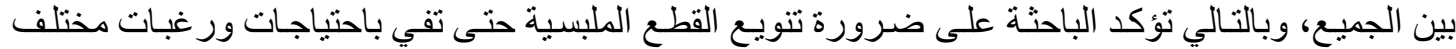

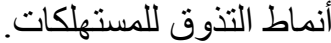

التوصيات: _ ـ الاهتمام بأخذ مرئيات الأطفال في تصميم الزخارف و الألوان و النقوش الخاصة بتنفيذ ملابسهم؛ لما وجد من تفاوت كبير بين أذواق الأطفال و المحكمين.

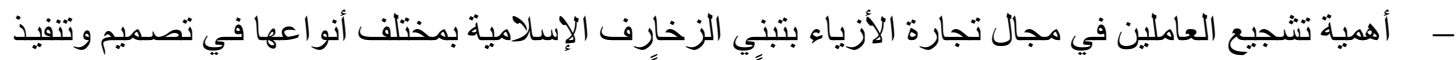
ملابس الفتيات، لتعزيز الهوية الإسلامية ونشر ها محلياً و عالمياً. 


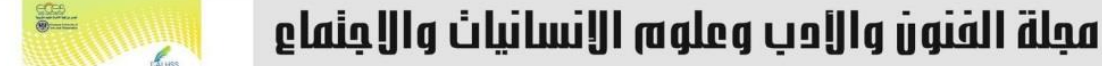 \\ Journal of Arts, Literature, Humanities and Social Sciences www.jalhss.com

ـ- التأكيد على ضرورة الاهتمام بتضمين الز خارف الإسـلامية سو اء في تتفيذ المنسوجات، أو تزبين الملابس للإناثاث و الذكور على حد سواء.

1. عسن، أ. ع \& , .زغلول، س. ع . . (2009) .عناصر الزخرفة في العصر الفرعوني كمصدر لتصميم

2. علي، س. ع .(2011) .الأبعاد التشكيلية لاعمال جون مبرو و و بول كلي كمصدر لتصديم و تتفيذ ملابس .مجلة علوم وفنون. 3. إبر اهيم، إ. (2015) إتجاهات حديثة في الاخراج الصحفي .القاهرة: دار الفجر للنشر و التوزيع.

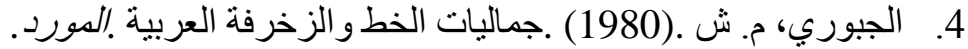

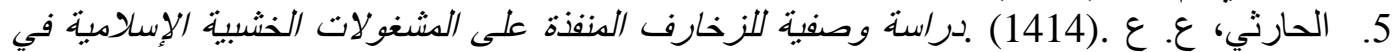

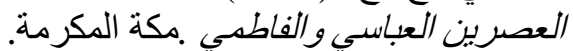

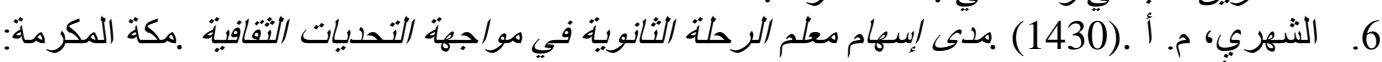
جامعة أُم القرى.

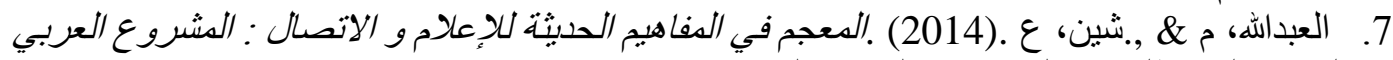

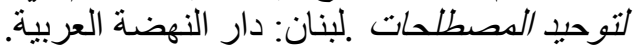
8. العتيبي، س. م .(2017) .ابتكار تصمبيات جلابيات نسائية مستوحاة من زخارف منطقة عسير . القصيم: جامعة القصيم. الفئر 9. الغامدي، ف. أ .(2004) .التحوبير في عناصر الزخرفه النباتيه الاسلامبه كمدخل تجريبي لإنتاج

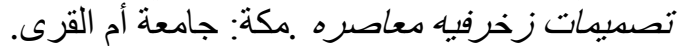

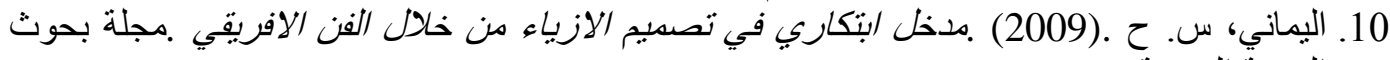
التربية النو عية.

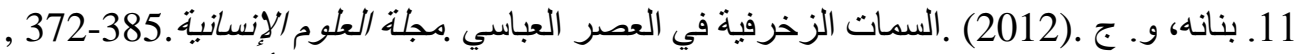

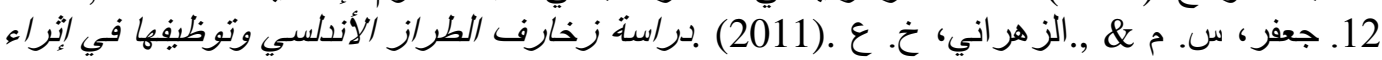
الملابس . مجلة بحوث من التربية النو عية.

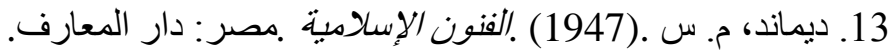
14. صكر ، أ. ع \& . .الجميلي، م. ك. .(2014) .العصر العباسي الأول قوة دولة وازدهار حضارة .بيروت: دار الكتب العلمية. 15. طه، ح. ح .(2003) ققابلية التحوبير كذاصبية فنبة في الخط العربي وكمدل لإثراء التصمبيات الزخرفبة . مصر ح: جامعة حلو ان كلية التربية الفنية.

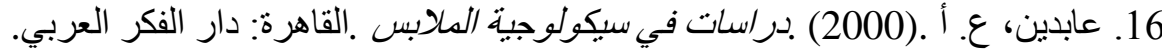

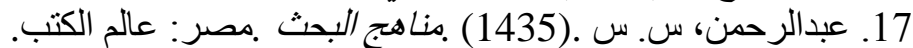

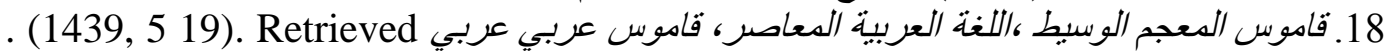
from

https://www.almaany.com/ar/dict/arar/\%D8\%A7\%D9\%84\%D8\%B2\%D8\%AE\%D8\%B1\%D9\%81/

19. قربان، م. ع .(2016) .تحوير شكل الطائر في الفن الإسلامي كمصدر لاستلهام حلي معدنية مموهة بالمبنا .المجلة التربوية الدولية المتخصصة.

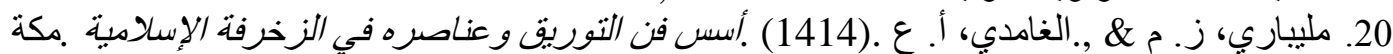
المكرمة: جامعة أم القرى.

\section{References}

1. Hassan, Prof. A., \& Zaghloul, S. P. (2009). Decoration elements in the Pharaonic era as a source for men's shirt design. Journal of Sciences and Arts - Studies and Research. 


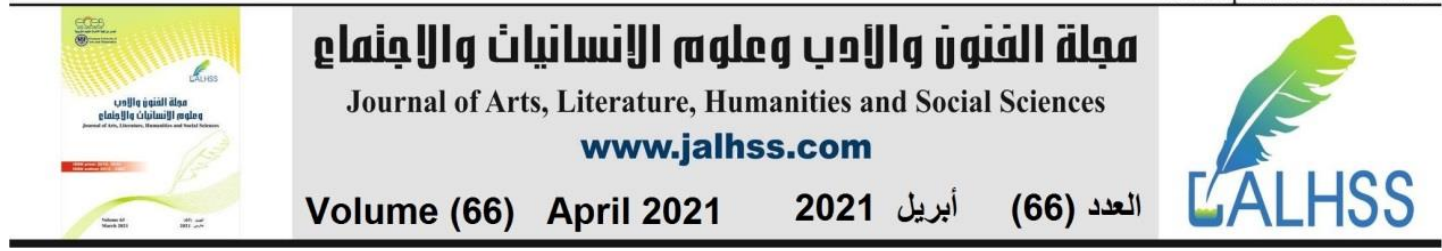

2. Ali, S. P. (2011). Plastic dimensions of the works of John Miro and Paul Klee as a source for designing and creating clothing. Science and Arts Journal.

3. Ibrahim, I. (2015). Recent trends in press production. Cairo: Dar Al-Fajr for Publishing and Distribution.

4. Al-Jubouri, M. U. (1980). Aesthetics of Arabic calligraphy and decoration. the supplier.

5. Al-Harthi, A. P. (1414). A descriptive study of the decorations executed on Islamic woodwork during the Abbasid and Fatimid eras. Mecca.

6. Monthly, m. a. (1430). The extent of the secondary trip teacher's contribution to meeting cultural challenges. Makkah Al-Mukarramah: Umm Al-Qura University.

7. Al-Abdullah, M., \& Shane, A. (2014). The Dictionary of Modern Media and Communication Concepts: The Arab Project for Standardizing Terminology. Lebanon: Arab Renaissance House.

8. Al-Otaibi, S. M. (2017). Creating women's Jalabiya designs inspired by the decorations of the Asir region. Al-Qassim: Al-Qassim University.

9. Al-Ghamdi, F. a. (2004). The modification in the elements of the Islamic plant decoration as an experimental input to the production of contemporary decorative designs. Makkah: Umm Al-Qura University.

10. Al-Yamani, S. H. (2009). An innovative approach to fashion design through African art. Journal of Specific Education Research.

11. Banana, W. C. (2012). Decorative features in the Abbasid era. Journal of the Human Sciences, 372-385.

12. Jafar, S. M., \& Al-Zahrani, k. P. (2011). Study the motifs of the Andalusian style and use them to enrich clothes. Journal of Specific Education Research.

13. Demand, M. s. (1947). Islamic arts. Egypt: Dar Al Maaref.

14. Saker, A. A., \& Al-Jumaili, M. K. (2014). The first Abbasid era is a power of a state and the prosperity of a civilization. Beirut: House of Scientific Books.

15. Taha, H. H. (2003). The ability to adapt as an artistic feature in Arabic calligraphy and as an input to enrich decorative designs. Egypt: Helwan University, Faculty of Art Education.

16. Abdeen, A. a. (2000). Studies in the psychology of clothing. Cairo: The Arab Thought House.

17. Abdul-Rahman, S. s. (1435). Research Methods. Egypt: The World of Books.

18. Al-Waseet Lexicon, Contemporary Arabic, Arabic-Arabic Dictionary. (1439, 5

19). Retrieved from https://www.almaany.com/ar/dict/arar/\%D8\%A7\%D9\%84\%D8\%B2\%D8\%AE\%D8\%B1\%D9\%81/

19. Qurban, M. P. (2016). Modifying the shape of the bird in Islamic art as a source of inspiration for enameled metal jewelry. The Specialized Educational International Journal, 81-94.

20. Melibari, G. M., \& Al-Ghamdi, A. P. (1414). Foundations of the art of securitization and its elements in the Islamic decoration. Makkah Al-Mukarramah: Umm Al-Qura University. 